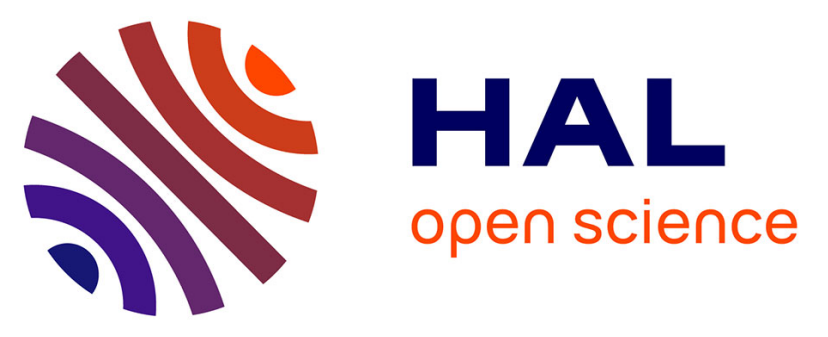

\title{
Immuno-Based Molecular Scaffolding of Glucose Dehydrogenase and Ferrocene Mediator on fd Viral Particles Yields Enhanced Bioelectrocatalysis ACS Paragon Plus Environment
}

Kristian Torbensen, Anisha Patel, Agnès Anne, Christophe Demaille, Laure Bataille, Thierry Michon, Eric Grelet

\section{To cite this version:}

Kristian Torbensen, Anisha Patel, Agnès Anne, Christophe Demaille, Laure Bataille, et al.. ImmunoBased Molecular Scaffolding of Glucose Dehydrogenase and Ferrocene Mediator on fd Viral Particles Yields Enhanced Bioelectrocatalysis ACS Paragon Plus Environment. ACS Catalysis, 2019, 9 (6), pp.5783-5796. 10.1021/acscatal.9b01263 . hal-02186135

\section{HAL Id: hal-02186135 \\ https://hal.science/hal-02186135}

Submitted on 17 Jul 2019

HAL is a multi-disciplinary open access archive for the deposit and dissemination of scientific research documents, whether they are published or not. The documents may come from teaching and research institutions in France or abroad, or from public or private research centers.
L'archive ouverte pluridisciplinaire HAL, est destinée au dépôt et à la diffusion de documents scientifiques de niveau recherche, publiés ou non, émanant des établissements d'enseignement et de recherche français ou étrangers, des laboratoires publics ou privés.

\section{(ㄷ)(i)}

Distributed under a Creative Commons Attribution| 4.0 International License 


\section{Immuno-Based Molecular Scaffolding of Glucose}

\section{Dehydrogenase and Ferrocene Mediator on $f d$ Viral}

\section{Particles Yields Enhanced Bioelectrocatalysis}

Kristian Torbensen ${ }^{1}$, Anisha Patel ${ }^{1}$, Agnès Anne* $^{*}$, Arnaud Chovin $^{1}$, Christophe Demaille*1,

Laure Bataille $^{2}$, Thierry Michon*2

Eric Grelet ${ }^{3}$

${ }^{1}$ Laboratoire d'Electrochimie Moléculaire, Université Paris Diderot, Sorbonne Paris Cité, Unité Mixte de Recherche Université - UMR 7591 CNRS, Bâtiment Lavoisier, 15 rue Jean-Antoine de Baïf, 75205 Paris Cedex 13, France

${ }^{2}$ UMR 1332 Biologie du Fruit et Pathologie, INRA, Université de Bordeaux, 71, avenue Edouard Bourlaux, CS 20032-33882 Villenave d'Ornon Cedex, France

${ }^{3}$ Centre de Recherche Paul-Pascal, UMR 5031 CNRS, Université de Bordeaux, 115 avenue Schweitzer, 33600 Pessac, France

* To whom correspondence should be addressed.

E-mail: anne@univ-paris-diderot.fr ; demaille@univ-paris-diderot.fr ; thierry.michon@inra.fr 


\begin{abstract}
A virus-based nanostructuring strategy is proposed for improving the catalytic performance of integrated redox enzyme electrodes. Random arrays of adsorbed filamentous $f d$ bacteriophage particles, used as scaffolds, are assembled onto gold electrode surfaces. The viral particles are endowed with functionally coupled enzymatic and redox properties, by the sequential immunological assembly on their protein shell of quinoprotein glucose dehydrogenase conjugated antibodies and ferrocene PEGylated antibodies. The resulting virus-scaffolded enzyme/redox mediator integrated system displays a large enhancement in the catalytic current generated per enzyme molecule (i.e. in enzymatic turnover) as compared to non-scaffolded integrated glucose oxidizing enzyme electrodes. The mechanism underlying the observed scaffolding-induced catalytic enhancement is deciphered. Confinement of the mediator on the viral scaffold enables fast electron transport rate and shifts the enzyme behavior into its most effective cooperative kinetic mode.
\end{abstract}

Keywords: bioelectrocatalysis, enzyme nanocarriers, bioelectrocatalytic viral particles, pyrroloquinoline quinone dependent glucose dehydrogenase, bioscaffolding

\title{
Introduction
}

Enhancing the catalytic activity of electrode-immobilized glucose oxidizing enzymes is key to the design of more sensitive glucose biosensors, and more powerful biofuel cell anodes. ${ }^{1,2}$ The glucose oxidase (GOx), and the much more active, and oxygen insensitive, pyrroloquinoline quinone (PQQ)dependent glucose dehydrogenase (PQQ-GDH), are amongst the most widely used redox enzymes for these important applications. A promising way to enhance their bioelectrocatalytic activity is to immobilize these enzymes on nanostructured electrode surfaces. ${ }^{3-7}$ The expectation is that mastering the 
surface architecture at the nanometer scale will provide a more-enzyme friendly environment, avoiding immobilization-induced denaturation. In addition, this may also improve the electrical communication between the redox enzymes and the electrode, notably if the enzyme can undergo direct electron transfer (DET) with the electrode material. ${ }^{6,7}$ Similarly, for integrated systems,${ }^{8}$ where the enzyme and its redox mediator are co-immobilized onto the electrode surface, nanostructuring can enhance the rate at which the mediator shuttles electrons from the electrode to the enzyme.

In seminal works regarding integrated systems, the catalytic activity of nanostructured electrode materials combined with hydrogel composites entrapping both enzymes and redox centers has been assessed. ${ }^{9-11}$ It has notably been shown that depositing GOx-containing redox hydrogels on carbon nanotubes microfiber networks, instead of on regular (non-nanostructured) carbon fibers, resulted in biofuel anodes displaying increased power density. ${ }^{9}$ An enhanced catalytic response was also observed by "dopping" with gold nanoparticles the electron conductivity of GOx containing redox-hydrogels. ${ }^{10,11}$ Other works considered carbon nanotubes ${ }^{12-14}$ and $\mathrm{ZnO}$ nanoparticles ${ }^{15}$ functionalized by ferrocene moieties as redox mediators for polymer-entrapped GOx. Another type of nanostructured integrated system, consisting of a mesoporous enzyme electrode, where ferrocene molecules were trapped in nanopores capped with GOx, was also described. ${ }^{16}$ Recently, PQQ-GDH has been covalently functionalized by a ferrocene mediator and immobilized on a quantum dot-decorated electrode, and a photo-electrocatalytic response was evidenced. ${ }^{17}$

In search of nanostructures offering a microenvironment potentially more enzyme-favorable than inorganic nanoparticles or porous electrodes, integrated systems based on DNA material have been developed. ${ }^{18-20}$ DNA hydrogels, incorporating GOx and a ferrocene mediator have notably been reported. ${ }^{18}$ DNA strands were also used as bio-scaffolds to assemble GOx and ferrocene relays. ${ }^{19,20}$

Even though many of the above works reported valuable results, new nanostructuring or scaffolding strategies have to be designed to improve further the catalytic performances of integrated enzyme electrodes. This is evidenced by the fact that, for every integrated system reported in literature, the apparent enzymatic turnover, i.e. the current generated per enzyme molecule, falls behind the turnover of 
the enzymes in solutions. This may result from the electron transport between redox relays being rate limiting, or from partial inactivation of the enzyme.

In that context, the aim of our work is to explore the possibility of using an original bottom-up scaffolding approach for improving the catalytic performances of electrode-supported glucose oxidizing enzymatic systems. This strategy makes use of viral particles as electrode-immobilized bio-scaffolds. The specific interest of using virus particles arises from their availability as perfectly monodisperse nanometer-sized particles and their highly ordered architectures enabling the topologically controlled assembly of enzyme molecules. Moreover, since the introduction of the concept of using viral particles as enzyme nanocarriers, ${ }^{21,22}$ preserved or improved catalytic performances for virus-supported or virusencapsulated enzymes, have been repeatedly reported, albeit almost exclusively for viral scaffolds dispersed in solution. ${ }^{23-29}$ The possibility of using viral particles as enzyme carriers for enhancing the catalytic response of electrode-supported enzymatic systems has, at the opposite, been little explored. In pioneering works, Wege et al. reported that adsorbing GOx-functionalized tobacco mosaic virus nanotubes onto a sensor electrode surface did not actually enhance $\mathrm{O}_{2}$-mediated catalysis, but significantly improved enzyme loading and sensor reusability. ${ }^{30-32}$ The design of a bioanode bearing a random mesh of M13 bacteriophage particles decorated with GOx has also been reported, but in that case the viral particles were "mineralized" by being gold coated in order to promote direct electron transfer $(\mathrm{DET}){ }^{33}$

Using an original immuno-based process, our group previously assembled, a non-integrated GOxbased system on $f d$ bacteriophage particles adsorbed on gold electrodes. ${ }^{34}$ What we address here is the benefit of scaffolding a much more complex, integrated, system on electrode-supported viral particles, by co-immobilizing a redox ferrocene mediator and the redox enzyme PQQ-GDH onto $f d$ bacteriophage particles. Even though multi-enzymatic constructs on viral particles, ${ }^{30,35-37}$ and virus particles decorated by redox moieties, have already been reported, ${ }^{38-40}$ this is the first time that viral particles are endowed with functionally coupled redox and enzymatic properties. 
Herein, $f d$ particles, randomly adsorbed on a gold electrode surface, were equipped with redox and enzymatic functions thanks to the sequential immunological assembly on their protein shell (capsid) of PQQ-GDH conjugated antibodies and redox-labeled antibodies. It is shown that confinement of the system's molecular components on the rod-like $f d$-nanoscaffold facilitates the mediated electronic communication between the enzyme and the supporting electrode, while fully preserving the enzyme activity, so that the electrocatalytic current is solely limited by the enzyme turnover rate. Moreover, confinement also results in shifting the PQQ-GDH kinetic behavior into its most effective cooperative mode. Consequently, the current generated by each of the GDH molecules incorporated in our $f d$ scaffolded system reaches exceptionally high values.

\section{Results and Discussion}

$F d$ bacteriophage is a filamentous virus, and a close cousin of the M13 bacteriophage which is widely used to design virus-based biosensors. ${ }^{41,42,43} \mathrm{Fd}$ differs from M13 only by a single-point mutation of the $12^{\text {th }}$ amino acid of each major coat protein, changing from asparagine (Asn) in M13 to aspartate (Asp) in $f d$. This results in a more negatively charged phage by about $30 \%$, having similar dimensions, $880 \mathrm{~nm}$ in length and $6.6 \mathrm{~nm}$ diameter (Figure 1). $F d$ bacteriophage can be used as an electroinactive rod-like enzyme nanocarrier, which displays the extra advantages of being robust, easy to handle and totally harmless to humans.

\section{Step by step immunological assembly of a PQQ-GDH integrated system on $f d$ particles.}

$F d$ particles were adsorbed from a stock solution prepared in a $10 \mathrm{mM} \mathrm{pH} 7.4$ phosphate buffer onto ultraflat template-stripped (TS) gold surfaces modified by a self-assembled layer of cysteamine (Figure 1). 


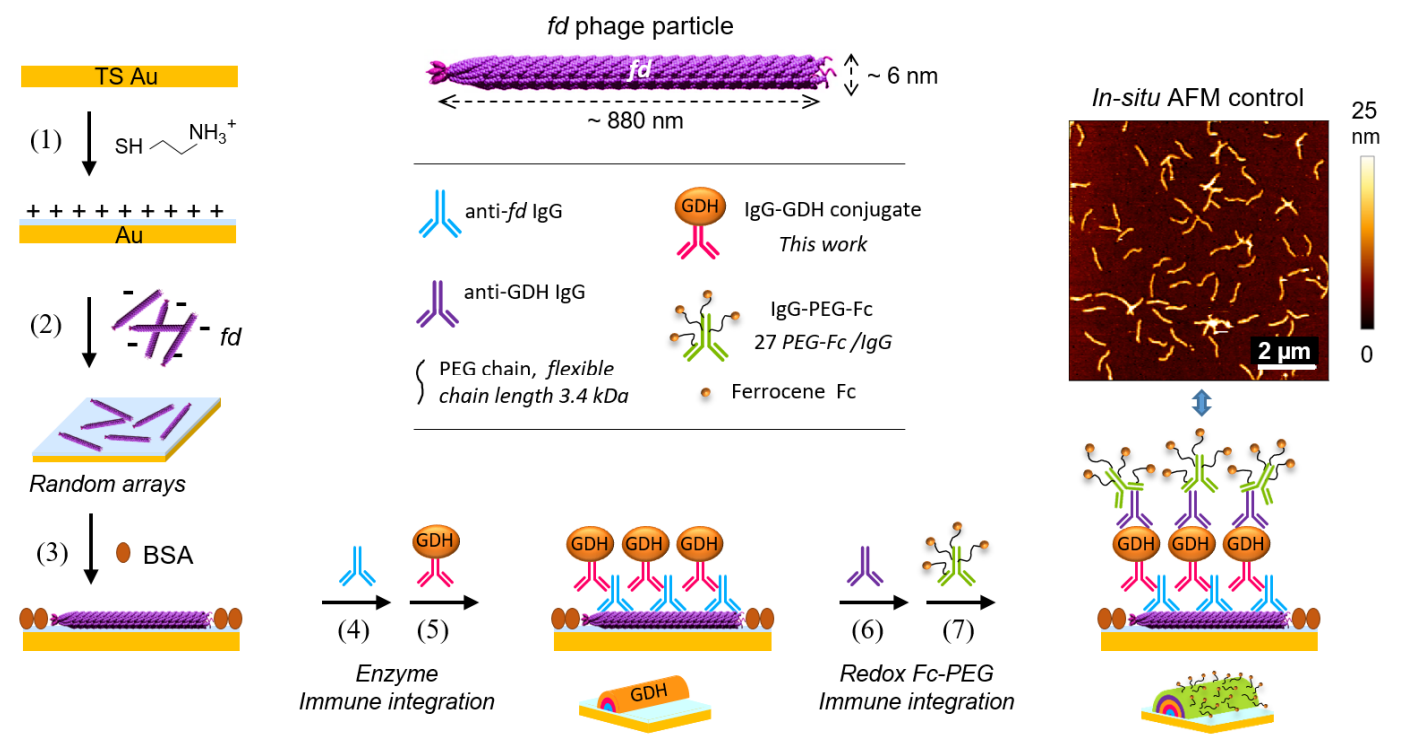

Figure 1. Assembly steps of the $f d$-scaffolded ferrocene-PEG-(Fc-PEG) / PQQ-GDH integrated system on a TS ultra-flat gold electrode surface. Right: In-situ AFM topography control image of a random array of Fc-PEG / PQQ-GDH immunodecorated fd particles on gold.

As shown in our previous work, electrostatic attraction at $\mathrm{pH} 7.4$ between the negatively charged $f d$ particles and the positively charged cysteaminated gold surface result in the irreversible adsorption of $f d$ on the surface to form random virus arrays. ${ }^{34}$ Immediately following the adsorption of the $f d$ particles, the surface was protected against non-specific adsorption by a BSA backfilling step. The surface was then exposed to a rabbit antibody (immunoglobulin $\mathrm{G}, \mathrm{IgG}$ ) directed against the coat protein of $f d$, in order for this IgG to assemble by immunological recognition onto the whole virus capsid.

Then, the surface was sequentially exposed to: a home prepared PQQ-GDH/anti-rabbit IgG conjugate, a commercial anti-GDH rabbit IgG, and finally to a redox-labelled antibody bearing polyethylene glycol (PEG) chains terminated by a ferrocene group $(\mathrm{Fc}) .{ }^{44}$ Note that based on our previous experience of immunological assemblies, ${ }^{45}$ we kept the concentration of the antibodies and the antigen-antibody reaction times high enough to ensure that a saturating "coating" of the virus particles by the IgGs was formed at every immunological immobilization step. This insures that a largely defect-free multimonolayer immunoconstruct is effectively assembled onto the virus capsid (see Supporting Information). Besides, as demonstrated earlier, ${ }^{45}$ and confirmed here, the antigen-antibody binding was found to be strong enough to confer very high stability to the immunological assemblies (see Methods section). In- 
situ AFM imaging of the surface allowed decorated $f d$ particles, forming a random array on the gold surface, to be identified (Figure 1).

The virus coverage, $\gamma_{f d}$, was determined by simple counting of the viral particles visible in the AFM image. $\gamma_{f d}$ was experimentally adjusted in the $0-2.5 f d / \mu \mathrm{m}^{2}$ range by controlling the concentration of the $f d$ solution used for the adsorption step.

The redox and enzymatic integrated system ultimately assembled on the $f d$ particles can, in principle, be schematically represented as shown in Figure 1. The successively assembled antibodies form concentric layers, color coded in Figure 1, around the virus scaffold. The expected "thickness" of each layer should correspond to the typical size of an $\mathrm{IgG}, \sim 10 \mathrm{~nm} .{ }^{46}$ The enzymatic component of the system, the GDH enzyme, is considered as forming a layer of its own, the third layer, also of about $\sim 10 \mathrm{~nm}$ thickness. ${ }^{47}$ The redox component of the system, the Fc-PEGylated antibody, comes as the last layer forming the outer "shell" of the assembly. Overall, the $f d$ particles supporting the Fc-PEG / PQQ-GDH system should thus display a hemicylindrical geometry $\sim 55 \mathrm{~nm}$ in radius and $\sim 900 \mathrm{~nm}$ in length.

We sought to experimentally confirm this schematic view of the $f d$-supported antibody construct by finely characterizing its structure and/or functions by an ensemble of techniques, as described below.

We found that AFM imaging alone was not well suited for monitoring the complete step-by-step assembly of the antibody construct on the $f d$-scaffold, as we observed that the height increment associated with the immobilization of antibody "layers" on the virus tended to become immeasurably small when more than three successive IgG layers were assembled. This result indicates that the multilayered antibody assembly on the virus is too soft to interact in a detectable way with the solid AFM tip. ${ }^{48}$

We thus turned to a more sophisticated local microscopy technique of our own, ${ }^{49}$ combining AFM with scanning electrochemical microscopy (SECM) in an original mediator-tethered (Mt ) configuration, for imaging individual virus particles decorated by the Fc-PEG / PQQ-GDH immunoconstruct. We previously demonstrated that this microscopy technique uniquely enables to map the distribution of redox functionalities on viral particles. ${ }^{39}$ 
Probing the redox function of the decorated $f d$ particles at the single viral particle scale by Mt/AFM-SECM microscopy.

A home-made combined local probe (tip), acting as both a force sensor and a microelectrode, and operating in tapping mode, was used to raster scan the TS gold surface immersed in phosphate buffer. The probe and surface were biased at potentials respectively largely anodic $\left(E_{t i p}=+0.3 \mathrm{~V} / \mathrm{SCE}\right)$ and cathodic $\left(E_{\text {sub }}=-0.05 \mathrm{~V} / \mathrm{SCE}\right)$ with respect to the standard potential of the Fc heads of the PEG chains $\left(E^{\circ}=0.15 \mathrm{~V} / \mathrm{SCE}\right)$. Simultaneously acquired topography and current Mt/AFM-SECM images of the surface are reproduced in Figure 2.

\section{Mt/AFM-SECM}
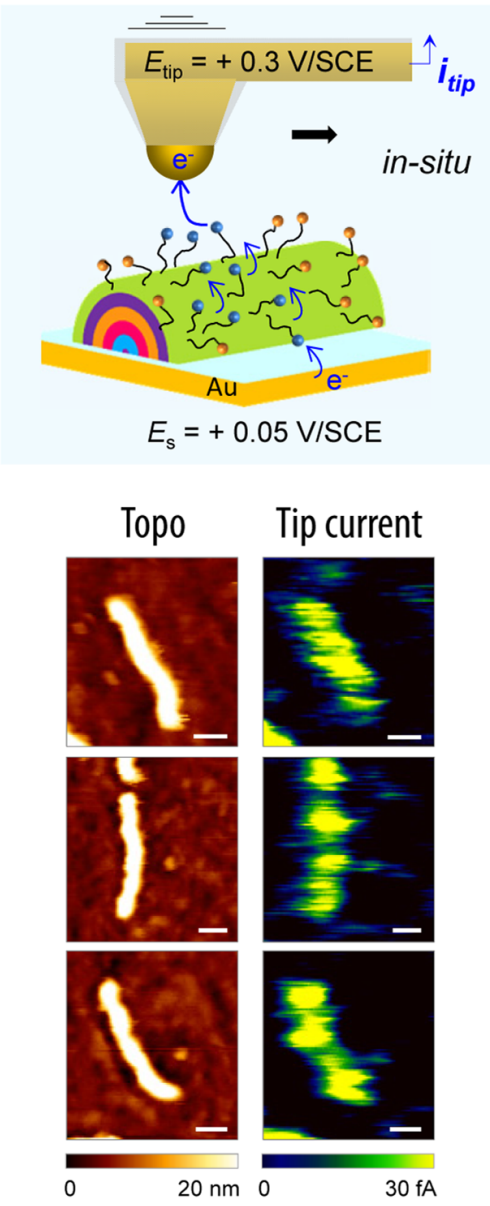

Figure 2. Mt/AFM-SECM images of the individual decorated $f d$ particles. Simultaneously recorded tapping-mode topography and tip current images. The contrast in the current image is generated by the electrochemical detection of the Fc heads by the scanning combined AFM-SECM probe (tip). Tip and TS gold surface potentials were respectively of: $E_{t i p}=+0.3 \mathrm{~V} / \mathrm{SCE}, E_{S}=$ $-0.05 \mathrm{~V} / \mathrm{SCE}$. Scale bar: $200 \mathrm{~nm}$. Imaging buffer: phosphate buffer. 
The topography images enabled to identify and locate individual decorated $f d$ particles, and to measure their apparent height $(\sim 20 \mathrm{~nm})$ and width $(\sim 150 \mathrm{~nm})$. These values are respectively under- and overestimates of the actual particle dimensions because of tip-sample interactions and convolution artefacts common to all AFM-based imaging techniques. The current images showed electrochemical tip current detection specifically at the location of the particles. This current reflects the electrochemical probing of the Fc-heads by the tip. It is generated by electrons originating from the TS gold surface, propagating along the capsid of the decorated $f d$ and ultimately collected by the tip, as schematized in Figure 2. Electron propagation over the few tens of nanometers high decorated virus particle is made possible by the swinging motion of the flexible PEG chains, coupled to electron exchange between neighboring Fc heads. ${ }^{39,49,50}$ Importantly, no current was detected if decorated $f d$ particles lacking the IgG-PEG-Fc were imaged, or if the tip potential was less than the onset oxidation potential of the Fc heads.

These results demonstrate unambiguously the presence of Fc-PEG chains, hence of the Fc-PEG-IgG, on the capsid of the decorated $f d$ particles. The observation that no current was recorded at locations on the surface away from the particles is an indication of the appropriate protection of the surface against nonspecific adsorption of the Fc-PEG-IgG. We also note that tip current was detected all along the length of the decorated $f d$ particles, confirming that the immunoassembly covers the entire capsid of the $f d$ particle. The fact that some sections of the $f d$ particles appear as brighter spots in the current image may indicate the artefactual formation of antibody clusters resulting from the glutaraldehyde fixation of the sample, a required pretreatment step for Mt/AFM-SECM imaging (see Methods section). Finally, it is worth mentioning that all of the $f d$ particles visible in topography images also appeared in the associated current images, showing that the immunological assembly process left no $f d$-particles un-decorated.

Even though we were able to visualize the Fc-PEG-IgG layer forming the outermost shell of the integrated virus-scaffolded assembly, extra characterization was needed in order to quantify the number of Fc-chains (hence of redox antibodies) decorating each $f d$ particle. For this, we turned to cyclic voltammetry. 


\section{Quantifying the number of ferrocene units decorating $f d$ particles by cyclic voltammetry.}

Cyclic voltamograms (CVs) were recorded at gold surfaces bearing arrays of $f d$ particles decorated by the Fc-PEG / PQQ-GDH system. The surfaces were mounted in a liquid cell containing $50 \mathrm{mM}$ Tris-HCl buffer $\mathrm{pH} 7.5$ as the electrolyte. A typical raw $\mathrm{CV}$ signal, recorded at a potential scan rate of $0.05 \mathrm{~V} / \mathrm{s}$, is presented in Figure 3B (red trace).
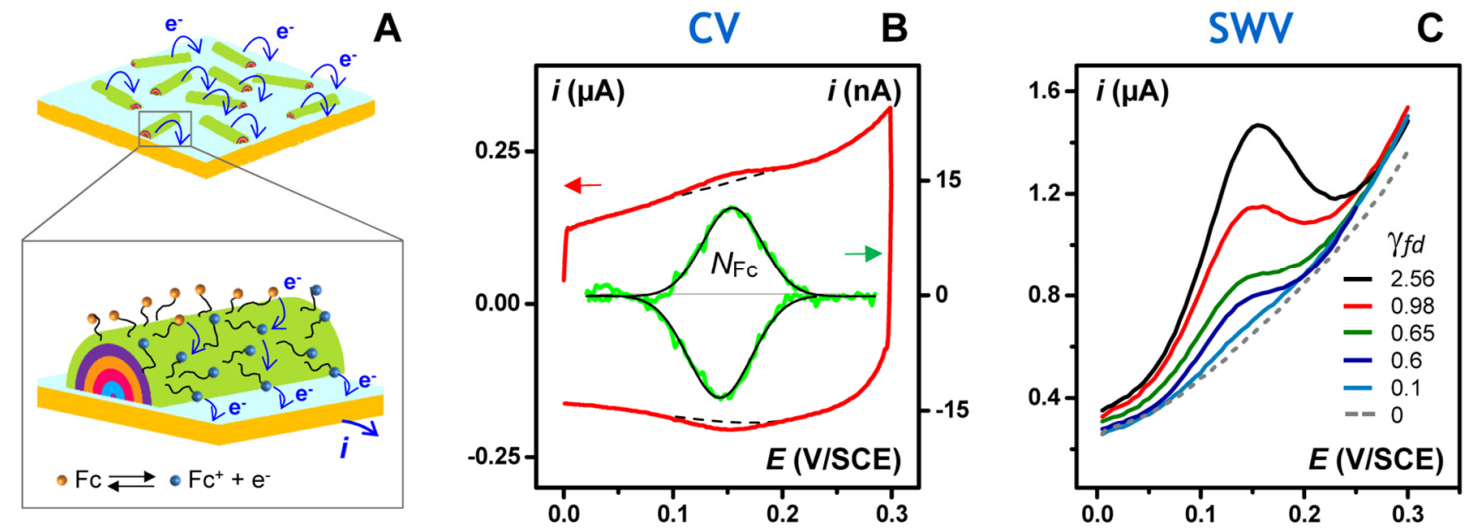

Figure 3. (A) Schematic representation of the electron transfer and transport processes occurring at the gold electrode surface supporting a random array of $f d$ particles decorated by the Fc-PEG / PQQ-GDH system, during the anodic scan of the electrode potential. (B) Cyclic voltammetry $(\mathrm{CV})$ response of the gold electrode supporting an array of the decorated $f d$ particles. The raw and background corrected CVs are plotted in red and green traces respectively. Scan rate, $0.05 \mathrm{~V} / \mathrm{s}$. $\gamma f d=2.56 f d$ particles $/ \mu \mathrm{m}^{2}$. (C) Square-wave voltammetry signal (SWV) of gold electrodes supporting decorated-fd particles at various coverages as indicated (in $f d$ particles per $\mu \mathrm{m}^{2}$ ). Medium: Tris buffer. SWV parameters: Amplitude, $25 \mathrm{mV}$; frequency, 25 $\mathrm{Hz}$; increment $5 \mathrm{mV}$.

The raw CV displays a pair of peaks superimposed on a large capacitive component that can be easily subtracted to yield the well-defined background-corrected signal shown in green trace in Figure 3B. On the corrected $\mathrm{CV}$, the peak-shaped signal is centered on a potential of $\sim 0.15 \mathrm{~V} / \mathrm{SCE}$, corresponding to the standard potential of the Fc heads, and the peak-to-peak potential separation is very small $(\sim 10 \mathrm{mV})$. Moreover, we verified that the intensity of the peaks was proportional to the scan rate, $v(0.01-0.2 \mathrm{~V} / \mathrm{s}$ range). All these characteristics evidence that the recorded CV signal corresponds to the response of surface confined Fc heads borne by the Fc-PEG-IgG of the construct, undergoing fast (Nernstian) electron transfer at the gold electrode surface. ${ }^{51}$ As a result, integration of the anodic peak of the CV yields the surface coverage in Fc-PEG, $\Gamma_{\mathrm{Fc}}$, which should depend on the number of decorated particles on the surface. 
To verify this relationship, we carried out CV measurements for a large number of gold surfaces bearing decorated $f d$ particles, randomly assembled at coverages varying from $\gamma_{f d}=0$ (no $f d$ particles) to $2.5 \mathrm{fd} / \mu \mathrm{m}^{2}$. In parallel to CVs we also recorded square wave voltammograms (SWVs) at these surfaces (Figure 3C). Indeed, SWV signals display a much lower background component than CVs, making it easier to probe the presence of the Fc heads from raw data (see Supporting Information). As seen in Figure 3C, the intensity of the SWVs was observed to increase with the virus coverage on the surface. The surface coverage in Fc heads, as determined by CV, obviously showed the same trend, as can be seen in Figure 4A, where experimental values of $\Gamma_{\mathrm{Fc}}\left(\right.$ number of $\left.\mathrm{Fc} / \mu \mathrm{m}^{2}\right)$ are plotted as a function of $\gamma_{f d}$.

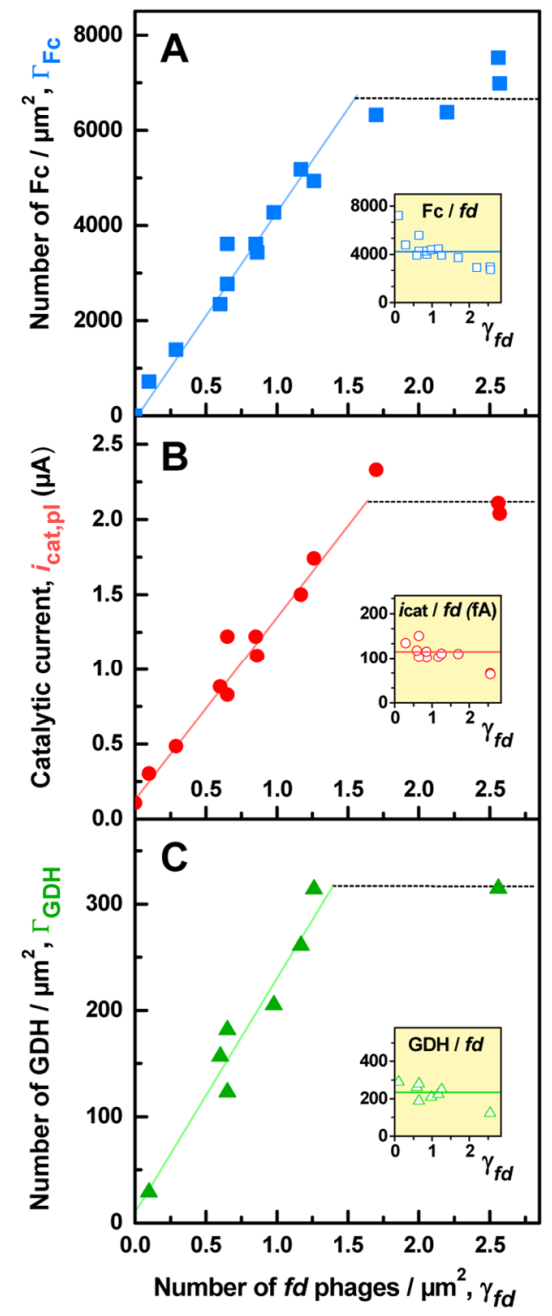

Figure 4. Structural and functional parameters characterizing gold surfaces bearing random arrays of $f d$ particles decorated by the Fc-PEG / PQQ-GDH system, as a function of the $f d$ surface coverage $\gamma_{f d .}$ (A) Fc head surface coverage, $\Gamma_{\mathrm{Fc}}$ as determined by CV. (B) Intensity of the CV catalytic plateau current $i_{\text {catpl }}$ in Tris buffer containing $30 \mathrm{mM}$ glucose. (C) GDH surface coverage as determined by the PQQ stripping method. The insets in (A), (B) and (C) respectively show the number of Fc heads, the intensity of the catalytic plateau current and the number of GDH molecules per $f d$ particle as a function of the $f d$ coverage $\gamma_{f d}$. 
One can see that, at low coverages corresponding to $\gamma_{f d}=0-1.5 f d / \mu \mathrm{m}^{2}, \Gamma_{\mathrm{Fc}}$ increases linearly with $\gamma_{f d}$. Also, when no virus is present $\left(\gamma_{f d}=0\right)$, almost no Fc is detected, demonstrating the absence of nonspecifically adsorbed IgG-PEG-Fc on the surface. At high coverages, corresponding to $\gamma_{f d}>1.5 \mathrm{fd} / \mu \mathrm{m}^{2}$, the $\Gamma_{\mathrm{Fc}} v s . \gamma_{f d}$ variation is seen to reach a plateau.

The linearity of the $\Gamma_{\mathrm{Fc}} v s . \gamma_{f d}$ variation observed for $\gamma_{f d}<1.5 f d / \mu \mathrm{m}^{2}$ brings extra evidence that the Fc heads detected in CV and SWV are borne by the $f d$ particles, and also shows that in this low $\gamma_{f d}$ region the average number of Fc-PEG chains borne by decorated $f d, N_{F c}$, does not vary with the virus coverage on the surface. $N_{F c}$ is given by the experimental $\Gamma_{\mathrm{Fc}} / \gamma_{f d}$ ratio, and is plotted as a function of $\gamma_{f d}$ in the inset in Figure 4A. One can see that $\sim 4000 \pm 400 \mathrm{Fc}$ heads are decorating each $f d$ particle. Since each redox IgG used in this study bears $\sim 24-30$ Fc-PEG chains, (see Methods section), one can conclude that as many as 120-180 IgG-PEG-Fc molecules are decorating each $f d$ particles.

The observation of a plateau region in the $\Gamma_{\mathrm{Fc}} . v s . \gamma_{f d}$ plot, occurring beyond a threshold value of $\gamma_{f d}=$ $1.5 \mathrm{fd} / \mu \mathrm{m}^{2}$, indicates that at higher virus coverages on the gold surface, decoration of the $f d$ particles becomes incomplete. As discussed in our previous work, ${ }^{34}$ this can be attributed to the fact that, above this threshold, a significant fraction of the randomly adsorbed $f d$ particles are intertwined and display limited accessibility for the antibodies. As previously shown, this problem can be fully alleviated by orientating the $f d$ particles, using simple molecular combing techniques. ${ }^{34}$ However, being solely interested in exploring scaffolding effects, we did not attempt this here, and shall therefore only discuss data obtained with electrodes characterized by $\gamma_{f d} \leq 1.5 \mathrm{fd} / \mu \mathrm{m}^{2}$.

Having ascertained and quantified the selective redox-immunodecoration of the $f d$ particles by the FcPEG chains, it is next necessary to evaluate the ability of the Fc heads to efficiently shuttle electrons from the gold surface toward the enzyme active site and to serve as enzymatic redox mediators. 


\section{Catalytic activity of the integrated Fc-PEG / PQQ-GDH system.}

Cyclic voltammetry was used to probe the catalytic activity of random arrays of $f d$ particles decorated by the integrated Fc-PEG / PQQ-GDH system. To this aim, glucose was injected in the liquid cell holding the gold surface bearing the decorated $f d$-nanoarrays, and CVs were recorded at $10 \mathrm{mV} / \mathrm{s}$.

As can be seen in Figure 5B, the injection of glucose resulted in a spectacular increase in intensity of the CV current, accompanied by a remarkable change in shape of the signal: from being dominated by the capacitive component (red trace), the current developed a marked S-shape (blue trace).
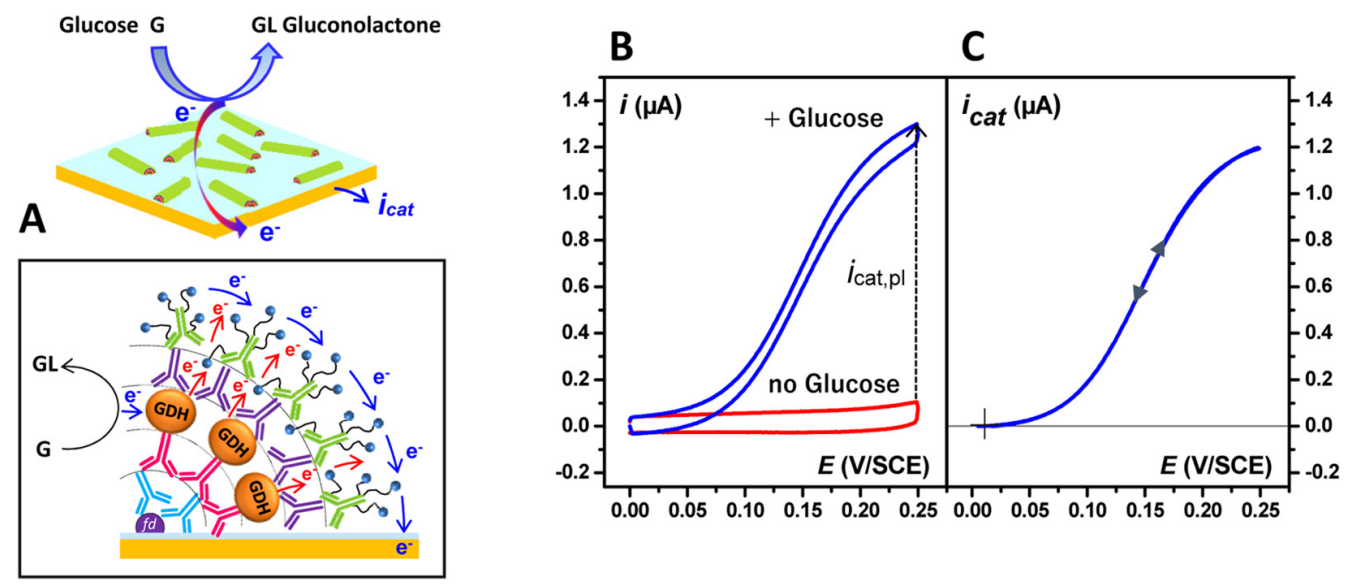

Figure 5. (A) Schematic representation of the catalytic oxidation of glucose by PQQ-GDH, coupled to electron transfer and transport processes occurring at the gold electrode surface supporting a random array of $f d$ particles decorated by the Fc-PEG / PQQ-GDH system. (B) Cyclic voltammetry (CV) response of the gold electrode supporting a random array of decorated $f d$ in the absence of glucose (red trace) and in the presence of $30 \mathrm{mM}$ glucose (blue trace). (C) Purely catalytic voltammogram derived from the CVs presented in (B) by subtracting the CV recorded in the absence of glucose from the signal recorded in its presence. Scan rate, $0.01 \mathrm{~V} / \mathrm{s} . \gamma_{f d}=0.85 f d$ particles $/ \mu \mathrm{m}^{2}$. Medium: Tris buffer.

This change in shape is characteristic of the catalytic response of an integrated system, where both the mediator and the redox enzyme are immobilized on the electrode. In the present case, and as schematically represented in Figure 5A, electrons resulting from the oxidation of glucose by GDH are transferred to nearby oxidized $\mathrm{Fc}$ heads $\left(\mathrm{Fc}^{+}\right)$, which play the role of enzymatic cofactors. Electrons are then relayed to the electrode surface by a composite charge transport process, implying physical elastic bounded motion of the Fc heads and electron self-exchanges between neighboring $\mathrm{Fc} / \mathrm{Fc}^{+}$heads. ${ }^{50}$ The high intensity and well-defined S-shape of the catalytic signal is thus a qualitative indication of the efficient coupling between electron transport and enzymatic catalysis in the $f d$-scaffolded immunoassembly. 
As demonstrated earlier for integrated catalytic system, ${ }^{52}$ in the absence of kinetic limitation due to electron transport, a catalytic voltammogram $i_{c a t} v s . E$, solely containing information on enzyme catalysis, can be conveniently obtained by subtracting the signal recoded in the absence of glucose from the catalytic signal obtained in its presence. The resulting subtracted signal, plotted in Figure 5C displays a remarkably well-defined, hysteresis-free $S$ shape, typical of purely catalytic voltammograms. This notably enables accurate determination of the catalytic plateau current, $i_{c a t, p l}$.

Values of $i_{c a t, p l}$ measured for several gold surfaces bearing decorated $f d$ nanoarrays, characterized by differing virus coverages, are plotted as a function of $\gamma_{f d}$ in Figure 4B. One can see that $i_{c a t, p l}$ increases linearly with $\gamma_{f d}$ up to $\gamma_{f d} \sim 1.5 f d / \mu \mathrm{m}^{2}$, and reaches a plateau for higher $\gamma_{f d}$ values. In the absence of viral particles $\left(\gamma_{f d}=0\right)$, a negligibly small catalytic current is recorded indicative of a trace amount of nonspecifically adsorbed IgG-PEG-Fc/IgG-GDH immunocomplexes on the electrode. These results evidence that the GDH molecules were specifically assembled on the virus capsid. The data presented in Figure 4B allow the average characteristic catalytic current generated by each individual $f d$ particle, $i_{c a t}^{f d}$, to be calculated from the expression: $i_{c a t}^{f d}=i_{c a t, p l} /(S \gamma f d)$, where $S$ is the geometric surface area of the

electrode. As seen in the inset in Figure 4B, a value of $i_{c a t}^{f d}=100 \pm 10 \mathrm{fA}$ per $f d$ particle is found for all of the surfaces examined, independently of their virus coverage.

\section{Assaying the number of GDH enzyme molecules decorating the $f d$-particles.}

Our strategy for "counting" the number of GDH enzyme molecules decorating the $f d$ particles is based on assaying the amount of its PQQ cofactor stripped from gold surfaces decorated by $f d$-nanorrays at various coverages of $f d$ (see Supporting Information for details). For this, the surfaces were first treated by a $0.1 \mathrm{M} \mathrm{pH} 2.5$ glycine buffer solution, in order to strip the antibodies off the viral scaffolds by disrupting antigen-antibody bonds. The recovered sample solution was then heated to $50{ }^{\circ} \mathrm{C}$ in order to trigger the spontaneous release of the non-covalently bound PQQ cofactors from GDH. ${ }^{53}$ The concentration of PQQ in the heat-treated sample was then assayed by introducing in solution an excess of apo-GDH. The activity of the thus reconstituted holo-GDH enzyme in solution was finally monitored 
spectrophotometrically in the presence of glucose and soluble electron donors (see Supporting Information). ${ }^{54,55}$

The PQQ-GDH used herein is a dimer, each monomer containing one PQQ moiety. Hence, $N_{G D H}^{\text {total }}$, the amount of PQQ-GDH molecules initially present on the surface (i.e. on the $f d$ particles) was derived simply by dividing the amount of assayed PQQ by a factor 2. The interest of this original protocol to quantify the amount of $f d$-immobilized PQQ-GDH is to be totally independent of the actual activity of the $f d$-bonded enzyme.

Figure 4C shows the value of the determined amount of PQQ-GDH, converted into an overall GDH coverage on the surface, $\Gamma_{\mathrm{GDH}}=N_{G D H}^{\text {total }} / S$, and determined for a series of gold surfaces characterized by various $\gamma_{f d}$ values. As can be seen, $\Gamma_{\mathrm{GDH}}$ increases linearly with $\gamma_{f d}$ for $\gamma_{f d}<1.5 f d / \mu \mathrm{m}^{2}$, indicating that in this low $\gamma_{f d}$ region, each $f d$ particle carries on average $N_{G D H}^{f d}=\Gamma_{\mathrm{GDH}} / \gamma_{f d} \sim 230 \pm 30$ GDH molecules, as shown in the inset.

The number of $230 \mathrm{GDH}$ per $f d$ particles found here is in fair agreement with the number of $\sim 180$ GOx molecules that, as showed previously, can be immunologically immobilized on randomly adsorbed $f d$ particles. ${ }^{34}$ Considering that the adsorbed $f d$ particle exposes half of its total capsid area of 18700 $\mathrm{nm}^{2},{ }^{56}$ and considering $\sim 100 \mathrm{~nm}^{2}$ as the footprint of an IgG, one would expect that about 100 rabbit anti$f d$ IgG can bind to each $f d$ particle. Since the anti-rabbit GDH conjugate is polyclonal, an estimate of 2-3 copies of it can thus possibly bind per anti-fd $\mathrm{IgG}$, resulting in an estimated saturating number of 200$300 \mathrm{GDH}$ molecules per $f d$. Hence it can be concluded that the packing density of GDH on the $f d$ particles is close to its maximum, i.e. the GDH-IgG conjugate forms a "saturating" layer on the virus capsid. This results confirms our previous observation, ${ }^{22}$ and is in agreement with other works, ${ }^{30,35,57}$ showing that affinity binding allows high yield decoration of virus particles by enzyme molecules. 


\section{Quantifying the catalytic efficiency of the scaffolded integrated system, on the basis of the current per enzyme molecule parameter.}

Cross-analysis of the plots presented in Figure 4, enables to derive the $i_{c a t}^{f d} / N_{G D H}^{f d}$ ratio, which is the value of the catalytic current generated by each GDH molecule incorporated in the $f d$-scaffolded integrated system, $i_{\text {cat }}^{G D H}=0.45 \pm 0.09 \mathrm{fA}$ per GDH molecule. Remarkably, this specific current per enzyme molecule is 7 to 15 times higher than the $0.03-0.065$ fA specific current that can be calculated for the most effective integrated PQQ-GDH system reported to date. ${ }^{58}$

This notable enhancement in specific current shows that electron transport, enzymatic activity and/or their coupling is superiorly efficient in our virus-scaffolded Fc-PEG / PQQ-GDH system compared to all other reported integrated systems.

Note that the performances of integrated enzymatic systems are often discussed in terms of current density, rather than on the basis of the current generated per enzyme molecule as we do here (albeit the notion of current per mg of enzyme has been recently introduced for describing the performance of an enzymatic biofuel cell). ${ }^{59}$ In order to achieve high current densities, it is quite common in literature that the equivalent of several hundreds of enzyme monolayers are immobilized on an electrode, meaning that the sub-optimal activity of the immobilized enzyme is artificially compensated by the enzyme loading of the system. We suggest that the current per enzyme criteria, as introduced here, is also used as a figure of merit for comparing integrated enzymatic systems, as it is a test of the ability of the entrapped enzyme to work at its optimal rate. Once optimal enzymatic conditions are defined, high current densities can then be reached with minimal enzyme loading, which is obviously beneficial considering the cost of enzymes. More generally, expressing the performance of a catalytic system as a function of the amount of catalyst involved is common in the field of electrochemical catalysis, ${ }^{60,61}$ but strangely enough disregarded in the field of bioelectrocatalysis.

The all-protein microenvironnment experienced by the enzyme in the on-virus immunological assembly, and the large enzyme-electrode separation, probably contribute to make our virus-scaffolded 
integrated system so catalytically effective. ${ }^{31,62}$ In order to reveal in more details what are exactly the beneficial factors at play, a thorough kinetic analysis of its catalytic response was carried out by cyclic voltammetry.

\section{Kinetic analysis of the catalytic activity of GDH in the virus-scaffolded integrated system.}

Cyclic voltammograms were recorded at a gold electrode bearing random arrays of $f d$-particles immunodecorated by the Fc-PEG / PQQ-GDH system for increasing glucose concentrations. As seen in Figure $6 \mathrm{~A}$, it was observed that the plateau current of the catalytic signal increased in intensity with increasing glucose concentration, $C^{\circ} g$, up to $30 \mathrm{mM}$, but then decreased when $C^{\circ} g$ was further increased.
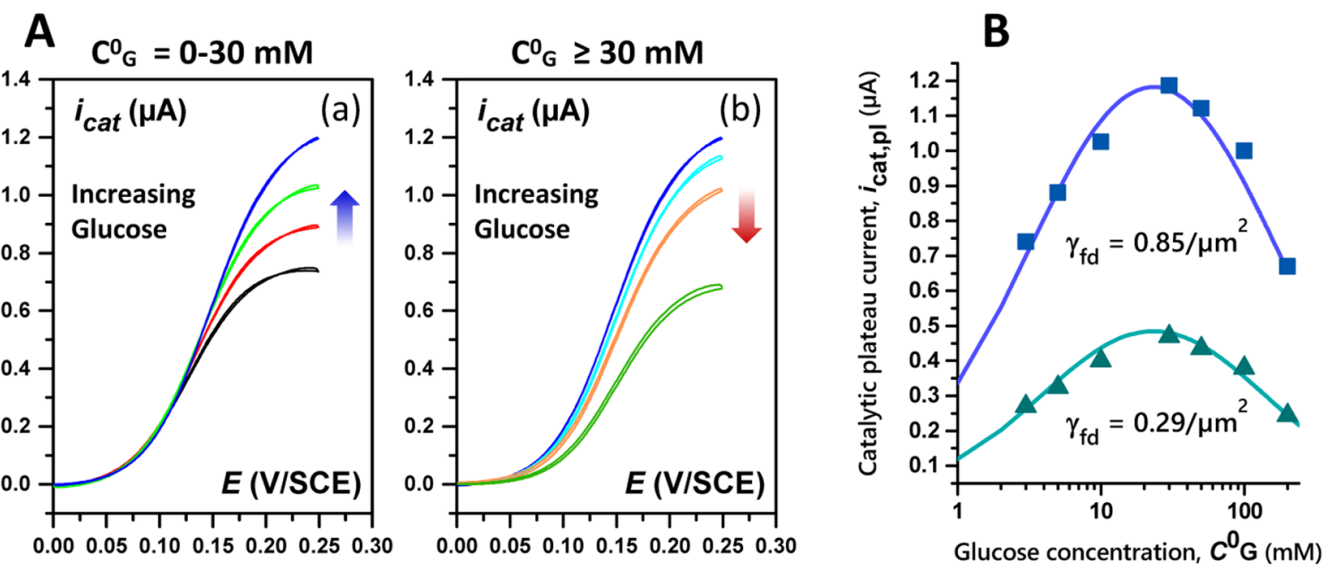

Figure 6. (A). Catalytic voltammograms recorded at a gold electrode bearing $f d$ particles decorated by the PQQ-GDH integrated system in Tris buffer containing glucose at the following concentrations: (a) 3 (black), 5 (red), 10 (light green), 30 (blue) $\mathrm{mM}$; (b) 30 (blue), 50 (cyan), 100 (orange), 200 (deep green) $\mathrm{mM}$ glucose. (B) Steady-state catalytic plateau currents $i_{c a t, p l}$ as a function of glucose concentration $C^{0} \mathrm{~g}$ for two surface coverages in decorated $f d$ particles, $\gamma f d$. Plain lines are the theoretical fits of Equation 2 to the experimental data using the here-determined kinetic constants reported in Table 1. Scan rate $(v=0.01 \mathrm{~V} / \mathrm{s})$.

This behavior is indicative of the well-documented substrate inhibition of PQQ-GDH. ${ }^{63,64}$ As a result, and as observed by others both for PQQ-GDH in solution, ${ }^{64}$ or reconstituted as monolayers on electrode surface, ${ }^{65}$ the variation of the catalytic plateau current, $i_{c a t, p l}$, with the bulk glucose concentration, $C^{\circ} g$, is bell-shaped, as seen in Figure 6B.

The kinetics of glucose oxidation catalyzed by the enzyme PQQ-GDH, using single electron ferrocene mediators as co-substrates, has been studied in great details in literature ${ }^{64}$ From these studies, it appears that PQQ-GDH displays a very complex catalytic behavior characterized by the co-existence of two 
kinetic modes. A non-cooperative mode, where no kinetic interaction exists between the monomers in the dimer constituting this enzyme (each monomer containing a PQQ active site), and a cooperative mode, where glucose binding by one of the monomeric units accelerates the catalytic action of the other. It was also shown that the non-cooperative and cooperative modes were prevailing at low and high mediator concentrations respectively. Later it was reported that, in either of these modes, the stationary catalytic current generated by PQQ-GDH molecules confined on an electrode surface is given by the following expression: ${ }^{65}$

$$
i_{c a t}=\frac{2 F S \Gamma_{G D H}}{\frac{1}{k_{o x} Q_{0}}\left(1+K_{i} C_{g}^{0}\right)+\frac{1}{k_{c a t}}+\frac{K_{M}}{k_{c a t} C_{g}^{0}}}
$$

where $C^{\circ} g$ and $Q_{0}$ are, respectively, the bulk glucose concentration and the oxidized mediator concentrations locally "seen" by the enzyme. Observation of a well-defined plateau in the catalytic CVs ascertains that glucose consumption is negligible, so that $C^{\circ} g$ can actually be taken as the bulk glucose concentration. $k_{c a t}$ is the catalytic constant of the enzyme, $K_{M}$ the Michaelis constant for glucose, $k_{o x}$ the second order rate constant corresponding to the oxidation of the enzyme by the mediator, and $K_{i}$ the equilibrium constant of the enzyme inhibition by glucose.

It was also shown that the individual values of the kinetic constants appearing in Equation 1 differed greatly between the non-cooperative and cooperative modes.

As reported previously, ${ }^{52}$ for integrated systems, when neither electron transfer from the enzyme to the electrode nor electron transfer at the electrode limit the overall kinetics, $Q_{0}$ is simply given by Nernst law. $Q_{0}$ is thus related to $C_{p}^{E}$, the total concentration of the mediator in both of its redox forms, and as "seen" by the enzyme, and also to the electrode potential $E$ by:

$$
Q_{0}=C_{p}^{E} /\left(1+\exp \left(-F\left(E-E^{\circ}\right) / R T\right)\right) \text {. }
$$

It thus appears legitimate to tentatively analyze the series of experimental catalytic voltammograms we recorded on the basis of Equation (1), or more conveniently of its reciprocal expression:

$$
1 / i_{c a t}(E)=\frac{1}{2 F S \Gamma_{G D H}}\left\{\frac{\left[1+\exp \left(-F\left(E-E^{\circ}\right) / R T\right)\right]}{k_{o x} C_{p}^{E}}\left(1+K_{i} C_{g}^{0}\right)+\frac{1}{k_{c a t}}\left(1+\frac{K_{M}}{C_{g}^{0}}\right)\right\}
$$


which is actually a linearized theoretical expression for the catalytic voltammogram.

Thus, as suggested by Equation 2, we plotted reciprocal of the catalytic current $i_{c a t}(E)$, measured along the experimental catalytic voltammograms for a wide range of $E$ values, as a function of the expression: $1+\exp (-x s i)$, where $x s i=F\left(E-E_{0}\right) /(R T)$. As can be seen in Figure 7 panel A, and as predicted by Equation 2, extremely well defined linear variations were then obtained for all of the voltammograms recorded for various glucose concentrations, $C^{\circ} g$.
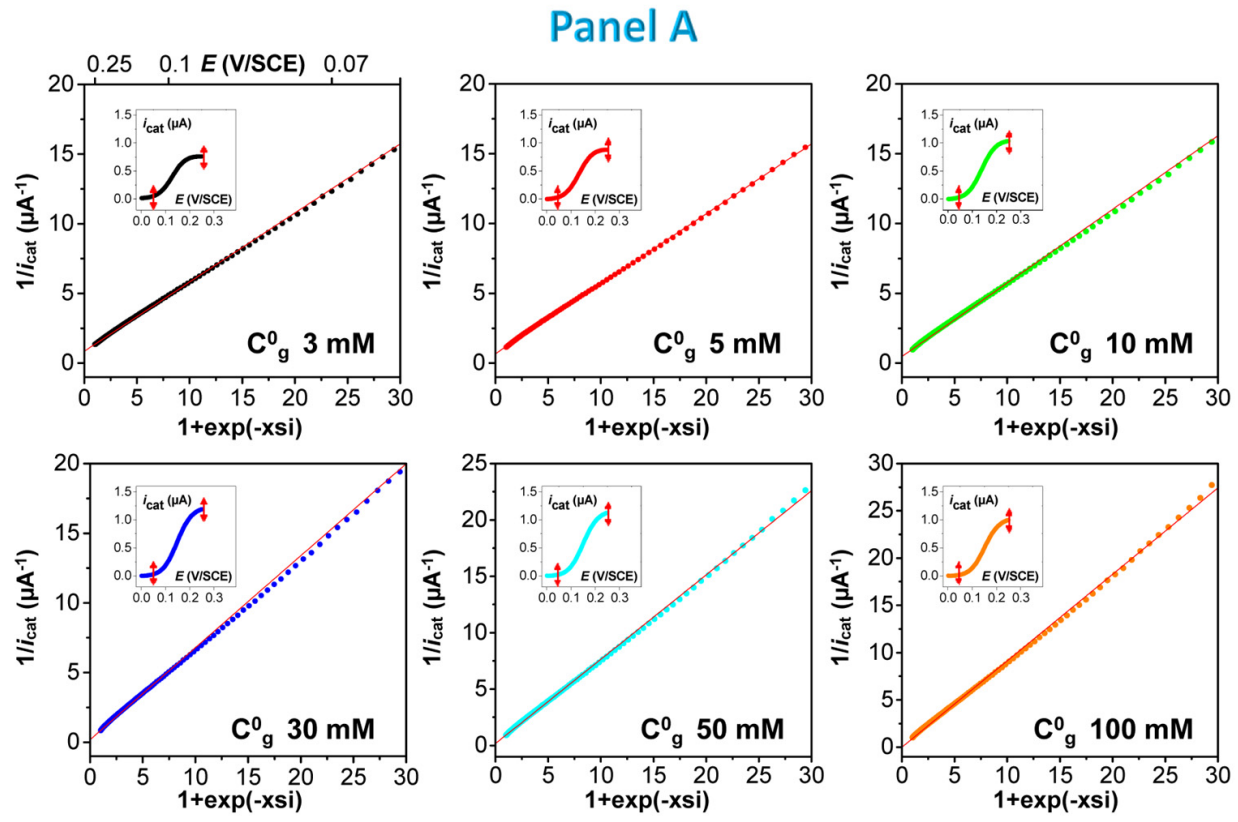

Panel B
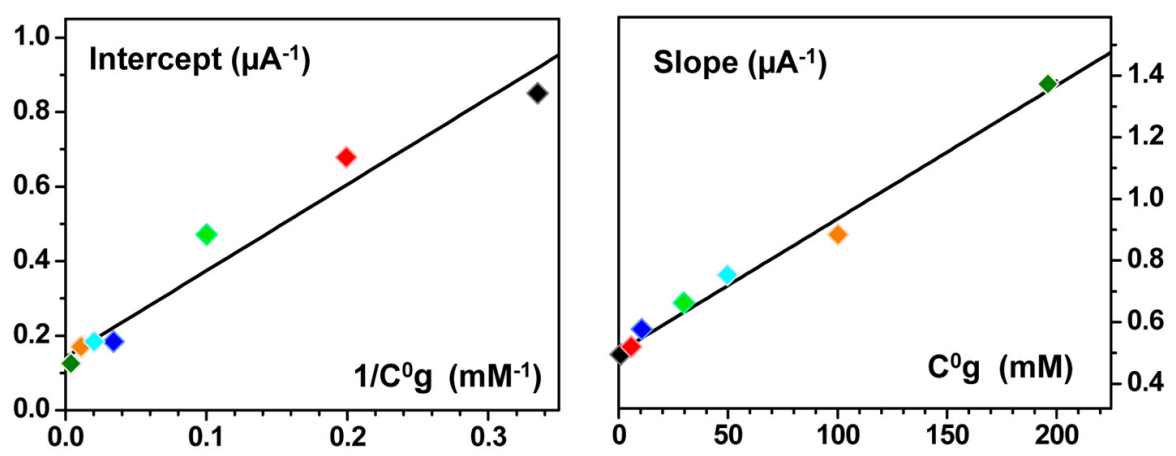

Figure 7. Kinetic analysis of the catalytic response of the integrated $f d$-scaffolded Fc-PEG / GDH system. (A) Primary plots where the reciprocal of the catalytic current $\left(i_{c a t}(E)\right)$ is plotted as a function of the $1+\exp (-x s i)$ term calculated all along the voltammograms shown in the insets (in the electrode potential region delimited by the double-headed red arrow shown). Each plot corresponds to a different glucose concentration, $C^{\circ} g$, as indicated. (B) Secondary plots showing the dependence of : (left) the intercept of the primary plots with $1 / C^{\circ} g$, (right) the slope of the primary plots with $C^{\circ}$ g. Scan rate, $0.01 \mathrm{~V} / \mathrm{s} . \gamma_{f d}=$ $0.85 f d$ particles $/ \mu \mathrm{m}^{2}$. Medium: Tris buffer. 
Observation of such linear Lineweaver-Burk-like "primary plots" validates our analysis and initial assumptions. In particular, this result shows that in our integrated system, the overall kinetics of PQQGDH can be phenomenologically described by the kinetic Equation 1, even though the kinetic mode adopted by GDH is not yet known.

From Equation 2, it can be seen that the theoretical expression for the slope, $s_{1}$, and origin, $o_{1}$, of the primary plots are respectively given by: $s_{1}=\frac{1+K_{i} C^{\circ} g}{2 F S \Gamma_{E} k_{o x} C^{\circ} p}$ and $o_{1}=\frac{1+K_{M} / C_{g}^{0}}{2 F S \Gamma_{E} k_{c a t}}$. Hence, the slopes of each of the lines shown in Figure 7 panel A were plotted as a function of the corresponding value of $C^{\circ} g$, and their origins as a function of $1 / C^{\circ} g$. As can be seen in Figure 7 panel B, two linear "secondary" plots were thus obtained, in agreement with theory.

Linear regression of the $o l v s .1 / C^{\circ} g$ secondary plot (left plot in Figure 7 panel B), yielded best-fit values of : $K_{M}=(14 \pm 2) \mathrm{mM}$ and $k_{c a t}=(8500 \pm 1100) \mathrm{s}^{-1}$. Similarly, linear fitting of the $s 1 v s .1 / C^{\circ} g$ variation (right plot in Figure 7 panel B) yielded values of: $K_{i}=(11 \pm 3) \mathrm{M}^{-1}$ and $k_{o x} C_{p}^{E}=(3 \pm 0.7) 10^{3} \mathrm{~s}^{-1}$.

Determining the value of $k_{o x}$ requires that the notion of the local concentration in mediator, $C_{p}^{E}$, is now clarified. $C_{p}^{E}$ actually corresponds to the average local concentration in Fc heads as "seen" by the enzyme active site. Its value depends on the actual Fc-PEG coverage on the viral particles, on the respective positions of the IgG-PEG-Fc and GDH-IgG conjugate "layers" in the assembly, but also on the elasticity of the PEG chain. As discussed in details in Supporting Information, a reasonable estimate for $C_{p}^{E}$ can be obtained based on our previously introduced elastic bounded diffusion model adapted to describe the behavior of IgG-bound Fc-PEG chains in immunoassemblies. ${ }^{52}$ We thus derived a value of $C_{p}^{E} \sim 12 \mu \mathrm{M}$, which yielded $k_{o x}=(2.5 \pm 0.6) 10^{8} \mathrm{M}^{-1} \mathrm{~s}^{-1}$.

The set of values obtained here for $k_{o x}, k_{c a t}, K_{M}$ and $K_{i}$ for $f d$-scaffolded integrated system are gathered in Table 1 (Column (I)), and compared to those determined by Limoges et al. for PQQ-GDH, using ferrocene methanol as a mediator, and functioning in both of its kinetic modes in solution (Column (IV) and Column (V)). ${ }^{65}$ 
Table 1. Sets of kinetic constants, and specific current per GDH molecule, characterizing the catalytic activity of PQQ-GDH in various systems, configurations and kinetic modes as indicated. Columns (I) to (III) (gray background) present data derived herein on the basis of Equation 1, columns (IV) and (V) present data from reference ${ }^{65}$.

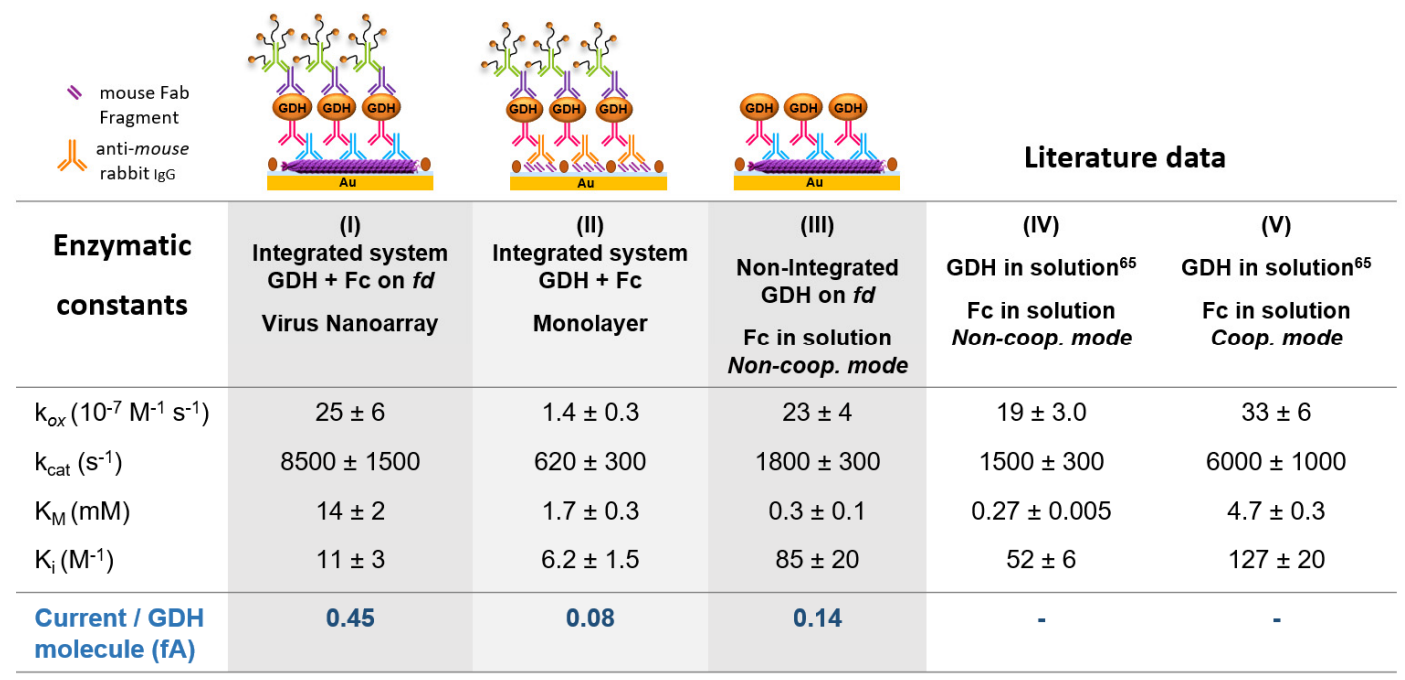

Comparing the data presented in Table 1, it appears that the values of both of the kinetic constants $k_{o x}$ and $k_{c a t}$ measured for our $f d$-scaffolded integrated system match those corresponding to the cooperative mode of PQQ-GDH in solution. The value found here for $K_{m}(14 \pm 2 \mathrm{mM})$ is somewhat higher than reported for the cooperative mode of PQQ-GDH $(4.7 \pm 0.3 \mathrm{mM})$, but mostly is $\sim 20$ times higher than the $K_{m}$ value reported for the non-cooperative mode of the enzyme. Interestingly, the value of the inhibition constant $K_{i}$ we find for our system is $\sim 10$ and $\sim 3$ times lower than reported for the cooperative and noncooperative modes respectively.

Hence, our global observation of a particularly high activity of PQQ-GDH assembled on $f d$ nanoscaffolds can now be understood on the basis of enzyme kinetics: within our virus-scaffolded assembly, the conditions are such that the enzyme spontaneously adopts its cooperative mode. Besides, as an extra (less decisive) benefit, the $f d$-supported enzyme displays somewhat lower inhibition with respect to glucose than it does in its native state.

The simplest explanation for this unprecedented result is that the dense molecular arrangement of the IgG-PEG-Fc and GDH conjugated antibodies on the $f d$-scaffold, results in a local concentration in Fc heads sufficiently high to favor the cooperative mode of the enzyme. Actually, one can evaluate from the 
above data that each GDH molecule is, on average, surrounded by $\sim 18 \pm 5 \mathrm{Fc}$ heads. The reason for a lower sensitivity to inhibition by glucose of the $f d$-scaffolded PQQ-GDH enzyme is not clear at this stage.

\section{Demonstrating that enhanced bioelectrocatalysis is due to scaffolding.}

In order to elucidate which part of these catalysis enhancing effects are due to confinement of the integrated system on the $f d$-scaffold, or to the particular molecular architecture of the immunological construct, we assembled the integrated system as an immunological monolayer on a planar gold surface (see scheme on top of Column (II) in Table 1). For this, the viral scaffold was replaced by a saturated monolayer of rabbit- Fab fragments, as they display approximately the same diameter $(\sim 5 \mathrm{~nm})^{46}$ as $f d$ particles. We then fully characterized the catalytic response of the electrode. As can be read in Table 1, bottom line, the current per GDH molecule recorded for such system was of only $0.08 \mathrm{fA}$, i.e. about 6 times lower than for the virus-scaffolded system. The kinetic constants derived from kinetic analysis were accordingly very low, even lower than expected for the non-cooperative mode of GDH. This latter result indicates that, when the system is assembled on a planar surface, the rate of electron transport, and not only GDH kinetics, contributes to the kinetic control of the catalytic current. Such is expected here since, in a planar monolayer configuration, mere elongation of the $30 \mathrm{~nm}$ long fully extended PEG chains cannot allow the $\mathrm{Fc}^{+}$-heads to directly collect electrons from the remote electrode surface. However, the fact that a catalytic current is nevertheless recorded suggests that hinge-like motion of the antibodies constituting the assembly provide an extra degree of freedom to the system, enabling electron transport from the enzyme to the electrode surface by electron hopping/elastic bounded diffusion.

The above comparative results demonstrate that the optimal catalytic response observed for the virusscaffolded integrated system can unambiguously be attributed to a beneficial nano-scaffolding effect.

In search of the mechanism underlying such an effect, we assembled a non-integrated two-IgG construct comprising solely the anti-fd antibody and the PQQ-GDH conjugate (see Column (III) in Table 1), and we interrogated its activity by cyclic voltammetry, using ferrocene methanol as a soluble mediator. We restricted our-selves to a low concentration in mediator $(3 \mu \mathrm{M})$, where the enzyme works in its non- 
cooperative mode, since previous work showed that for higher mediator concentrations glucose diffusion partially controls the catalytic CV signals, which interferes with kinetic analysis. ${ }^{65}$ The kinetic and thermodynamic constants we determined for the non-integrated scaffolded system are reported in Table 1, Column (III). Comparing the data presented in Column (III) and Column (IV) shows that the activity of PQQ-GDH is virtually the same whether the enzyme is scaffolded on the $f d$ particles or free in solution. This result confirms that the immunological assembly process fully preserves the activity of the enzyme, but also that scaffolding by itself does not enhance the catalytic performances of PQQ-GDH. Hence, we can conclude that the catalytic enhancement effect observed here for the integrated system is due to the confinement of both the enzyme and the redox mediator on the $f d$-scaffold. Our interpretation is that this effect is rooted in the nanoscale hemicylindrical geometry of the $f d$-scaffolded assembly which, as represented schematically in Figure 5A, facilitates access to the electrode for the Fc heads, but also accelerates electron transport within the assembly. This not only cancels the kinetic limitations due to electron propagation to/from the enzyme but also, by insuring a high local concentration in Fc heads in the vicinity of the enzymatic sites, drives PQQ-GDH toward its most effective catalytic mode.

We believe that the present work is a rare example where the effect of enzyme nano-scaffolding could be so clearly evidenced, and explained on sound enzyme kinetics and (nano)-topological basis. This is the first time that such an effect is evidenced for a fully integrated enzymatic system.

\section{Conclusion.}

It has been shown herein that assembling an integrated enzymatic system on a viral nanoscaffold strongly enhances its catalytic performance compared to non-scaffolded systems. We elucidated the physical reason underlying such a catalytic improvement in the present case: the hemicylindrical arrangement of the system's molecular components on a nanometer-sized rod-like scaffold enhances the rate of mediated electronic communication between the enzyme and the supporting electrode. As a result, the only kinetic limitation to the current generated by the integrated system is enzyme kinetics. As a benefit of the enzyme-friendly microenvironment provided by the immunological assembly, the enzyme 
PQQ-GDH can remain fully active. Moreover, confinement of the Fc-PEG on the virus scaffold results in a high local mediator concentration, which shifts the enzyme behavior into its most effective cooperative mode. Consequently, the current generated by each of the GDH molecules incorporated in our $f d$-scaffolded system reaches its maximal, enzyme kinetics limited value, which significantly exceeds the current-per-enzyme molecule generated by other integrated PQQ-GDH systems reported in literature. More generally, we are not aware of any glucose oxidizing immobilized PQQ-GDH electrode where the enzyme was shown to work in its high-current generating cooperative mode.

Although the present work is of fundamental nature, it sets some rules for improving the performances of PQQ-GDH integrated glucose biosensors and bioanodes, as we showed that optimal current-perenzyme is achievable via virus particle-based nanostructuring of enzyme electrodes. However, for these applications high current densities is also required, which is typically achieved in literature by immobilizing the equivalent of multiple enzyme layers. Hence, a possible development of the present work would be forming multilayers of PQQ-GDH decorated $f d$ particles, using for example layer by layer electrostatic assembly of $f d$ /polyelectrolyte polymers, ${ }^{66}$ to ensure both optimal enzyme activity and high current density.

\section{Materials and methods}

\section{Biological Material.}

Virus particles. Fd viruses were grown and purified as described elsewhere. ${ }^{67}$ Virus suspensions were then concentrated by ultracentrifugation $(200000 \mathrm{~g})$ and redispersed in a stock solution of about $4 \mathrm{mg} / \mathrm{mL}$ as measured by spectrophotometry with an absorption coefficient of $3.84 \mathrm{~cm}^{2} / \mathrm{mg}$ at $269 \mathrm{~nm}$. To control the ionic conditions, the fd suspension was then extensively dialyzed against $10 \mathrm{mM}$ sodium phosphate buffer $\mathrm{pH} 7.4$ and stored at $4^{\circ} \mathrm{C}$ until further use.

Antibodies. The anti-fd polyclonal antibody (Immunoglobulin G, IgG) produced in rabbit was obtained from Sigma-Aldrich. The anti-rabbit GDH-IgG conjugate was prepared in-house by conjugating PQQGDH to a polyclonal goat anti-rabbit IgG, as detailed in Supporting Information. The anti-GDH 
polyclonal antibody was custom produced in rabbit by Genosphere Biotechnologies using apo-GDH monomers as antigens (see Supporting information). The goat anti-rabbit antibody to be conjugated with GDH or Fc-PEG chains, and the bovine serum albumin (BSA) (IgG-free grade) blocking agent were from Jackson ImmunoResearch Laboratories.

Enzymes. PQQ-GDH to prepare the IgG-GDH conjugate was produced from Acinetobacter calcoaceticus and purified as detailed in Supporting Information. Apo-GDH (GD-2) used for the PQQ assays was acquired form Sekisui enzymes.

Chemicals and solutions. All chemicals were analytical grade Sigma-Aldrich products and used as received, expect for PQQ that was a gift from the group of Dr. Benoit Limoges. All solutions were prepared with double-deionized water (18.2 $\mathrm{M} \Omega \mathrm{cm}$ resistivity, TKA Micro-Pure UV). Two buffer solutions were used: $10 \mathrm{mM}$ phosphate buffer at $\mathrm{pH} 7.4$ (phosphate buffer), and $50 \mathrm{mM}$ Tris-HCl buffer at $\mathrm{pH}$ 7.5. Phosphate buffer was used for the preparation of the $f d$ bacteriophage solutions and of the anti$f d$ antibody solutions employed for the assembly of the $f d$-scaffolded integrated system. Phosphate buffer was also the imaging medium for the in-situ AFM and AFM-SECM experiments. Tris buffer was used to prepare the solutions of GDH-IgG conjugate, of anti-GDH IgG and of Fc-PEG-IgG, required for the successive system assembly steps. Tris buffer was also the supporting electrolyte for the CV and SWV experiments. We chose Tris buffer over phosphate for these solutions/experiments since we observed increased stability of PQQ-GDH activity in Tris. All antibody solutions contained $1 \mathrm{mg} / \mathrm{ml} \mathrm{BSA.} 0.01 \%$ sodium azide was added as a preservative to the antibody solutions if used or stored for longer than a few hours at room temperature. All solutions and systems were protected from light with aluminum foil during investigation and storage.

Preparation and characterization of the redox secondary antibody, IgG-PEG-Fc. Fc-PEG chains were covalently conjugated to goat anti-rabbit IgGs by reacting the NHS activated ester of a home synthesized NHS-PEG3500-Fc chain with the amino groups of the IgG species, as previously described. ${ }^{44}$ The purified IgG-PEG-Fc product used in this study is decorated by a number of Fc-PEG molecules per IgG protein, $\mathrm{n} \sim 27 \pm 3$, as determined by MALDI-TOF MS. Briefly, the IgG-PEG-Fc sample and its 
starting IgG were (after reconstitution in a $0.1 \mathrm{M}$ ammonium acetate buffer) analyzed by MALDI-TOF MS on a UltrafleXtreme mass spectrometer (Bruker Daltonics). Sinapic acid (Aldrich) at a concentration of $45 \mathrm{mM}$ in 50:50 water/acetonitrile $(0.05 \% \mathrm{TFA})$ was used as a matrix. MALDI-TOF (positive ion mode) $\mathrm{m} / \mathrm{z}$ data: Starting $\operatorname{Ig} G$, Singly charged ion $\mathrm{M}^{+} 147121$, Doubly charged ion $\mathrm{M}^{2+} 73179-\operatorname{Ig} G^{-}$ PEG Fc conjugate, Singly charged ion $\mathrm{M}^{+} 253675$ Doubly charged ion $\mathrm{M}^{2+} 126337$. Calculated $\mathrm{M}^{+}$for $\left[\mathrm{IgG}+27.3 \mathrm{PEG}_{3500}-\mathrm{Fc}\right] \sim 253600$ (knowing that the average molecular mass for the Fc-PEG 3500 chain is $\sim 3900)$.

Production of GDH, preparation and characterization of the GDH-IgG conjugate. See Supporting Information.

Preparation of the ultra-flat gold electrodes. Ultra-flat gold surfaces were produced by templatestripping of a $200 \mathrm{~nm}$ thick gold layer deposited on mica, as previously described. ${ }^{68}$ A perforated Teflon adhesive mask was glued onto the surface in order to define a $4 \mathrm{~mm}$ diameter disk-shaped electrode. All subsequent surface modification steps were carried out by depositing/rinsing with $\sim 20 \mu \mathrm{L}$ drops of solutions confined to the electrode area by the hydrophobic Teflon mask.

Preparation of cysteaminated-gold surfaces. A $20 \mu \mathrm{L}$ drop of a $5 \mathrm{mM}$ cysteamine hydrochloride (HS$\left.\left(\mathrm{CH}_{2}\right)_{2}-\mathrm{NH}_{3}{ }^{+}, \mathrm{Cl}^{-}\right)$solution in water was left in contact with the electrode for $2 \mathrm{~h}$ under a water-saturated nitrogen atmosphere. The surface was then thoroughly rinsed by droplet replacement of cysteamine with water (twice) and then with phosphate buffer (twice). Drop replacement was cautiously carried out to avoid drying of the surface. Note, thiol functionalized surfaces were kept under a water-saturated nitrogen atmosphere in all subsequent assembly steps to prevent oxidative desorption of the cysteamine layer from the gold surface.

Adsorption of random $\boldsymbol{f} \boldsymbol{d}$ nanoarrays on cysteaminated gold. A $20 \mu \mathrm{L}$ solution of phosphate buffer containing $f d$ particles at 0.1 to $1.7 \mu \mathrm{g} / \mathrm{mL}\left((0.4\right.$ to 7.0$) \times 10^{10}$ phage particles $\left./ \mathrm{mL}\right)$ was deposited onto the cysteaminated gold surface for 5 minutes. The surface was then rinsed by two droplet replacement steps and left under phosphate buffer for 10 minutes for desorption of any weakly bound material. 
Protective BSA backfilling. $F d$ bearing surfaces were backfilled with a protective BSA layer by adsorption from a $20 \mu \mathrm{L}$ drop of $2 \mathrm{mg} / \mathrm{mL}$ BSA in phosphate for $1 \mathrm{~h}$ followed by two 10 minutes rinsing steps by drop replacement with phosphate buffer.

Assembly of the anti-fd antibody. The surface was left in contact for $1 \mathrm{~h}$ with a $20 \mu \mathrm{L}$ droplet of a 2 $\mu \mathrm{g} / \mathrm{mL}\left(\sim 0.810^{13}\right.$ molecules $\left./ \mathrm{mL}\right)$ solution of the anti-fd rabbit antibody. After two 10 minutes drop replacement rinsing steps, the surface was stored overnight at room temperature in the dark under a phosphate buffer solution containing $1 \mathrm{mg} / \mathrm{ml} \mathrm{BSA}$ and $0.01 \%(\mathrm{w}: \mathrm{v})$ sodium azide. This overnight storage/desorption step was found to be important for reducing non-specific binding of subsequent antibodies onto the surface.

Assembly of the PQQ-GDH conjugated antibody. A $20 \mu \mathrm{L}$ droplet of a $5 \mu \mathrm{g} / \mathrm{ml}\left(\sim 1.210^{13}\right.$ molecules/mL) anti-rabbit GDH-IgG conjugate in Tris buffer was left in contact with the surface for $2 \mathrm{~h}$. Two drop replacement rinsing steps with Tris buffer containing $1 \mathrm{mg} / \mathrm{mL}$ BSA followed.

Assembly of the anti-GDH antibody. The surface was left in contact for $1 \mathrm{~h}$ with $20 \mu \mathrm{L}$ of a $5 \mu \mathrm{g} / \mathrm{ml}$ solution of the rabbit anti-GDH IgG in Tris buffer. Rinsing was then carried out by drop replacement with Tris buffer containing $1 \mathrm{mg} / \mathrm{mL}$ BSA.

Assembly of the IgG-PEG-Fc antibody. $20 \mu \mathrm{L}$ of a $20 \mu \mathrm{g} / \mathrm{ml}$ solution of the home prepared anti-rabbit IgG-PEG-Fc in Tris buffer were deposited on the surface, the assembly reaction was left to proceed overnight at $4^{\circ} \mathrm{C}$.

When required, the surfaces were stored at $4^{\circ} \mathrm{C}$ in Tris buffer, being placed in a water-saturated nitrogen atmosphere.

Assaying the amount of PQQ-GDH molecules immuno-scaffolded on $\boldsymbol{f d}$-particles. The assay protocol developed in this work is fully described in Supporting Information. Briefly, the antibodies of the immunoassembly are stripped off the $f d$-scaffolds, PQQ is thermally released from the IgG-GDH conjugate and assayed spectrophotometrically by an enzymatic method. 
AFM imaging. Tapping mode AFM images were acquired with a Nanowizard II microscope (JPK, Germany). In-situ (i.e. in phosphate buffer) imaging was carried out with V-shaped contact mode probes (MLCT-AUMN or MSNL-10, Bruker, spring constant $0.1 \mathrm{~N} / \mathrm{m}$, tip curvature $20 \mathrm{~nm}$ ).

AFM-SECM imaging. Mt/AFM-SECM images were acquired using the JPK Nanowizard II microscope operated in AFM-SECM mode as previously described. ${ }^{39}$ The AFM-SECM tips were hand-fabricated according to a procedure detailed elsewhere. ${ }^{69}$ The standard JPK electrochemical liquid cell contained $900 \mu \mathrm{L}$ of filtered phosphate buffer solution, and was equipped with a platinum wire as a counterelectrode, and a micro $\mathrm{Ag} / \mathrm{AgCl}$ reference electrode. All potentials in this work are reported versus the $\mathrm{KCl}$ saturated calomel electrode reference SCE. A home-made bipotentiostat was used to control independently the potential applied to the TS gold surface and to the electrochemical tip, and to measure the tip current. The tip current signal was passed through a $10 \mathrm{~Hz}$ low-pass analogue filter. The current images were first order flattened and a light gaussian filter was applied. Images shown in text were processed using the JPK software.

Electrochemical analysis. The surface was mounted in a standard JPK electrochemical liquid cell. Cyclic voltammograms (CVs) were recorded with a CHI630C electrochemical workstation, in a three electrode configuration, using the platinum wire counter electrode encased in the JPK cell, and a standard KClsaturated calomel electrode (SCE) inserted in the middle of the cell. Temperature of the air-conditioned room was around $22{ }^{\circ} \mathrm{C}$. Measurements were carried out under ambient atmosphere, PQQ-GDH being insensitive to oxygen. Note, the stock solutions of glucose in Tris buffer were allowed to mutarotate overnight. When not in use the electrodes bearing the Fc-PEG / PQQ-GDH system were stored at $4{ }^{\circ} \mathrm{C}$ in Tris buffer. Upon one week storage, a maximal loss of $\sim 15 \%$ in catalytic activity was typically observed.

\section{Supporting Information Available}

Detailed experimental protocol for assaying the number of enzyme molecules borne by the viral particles. Demonstrating that the immunoassembly process yields saturated antibody layers onto the viral particles. 
Correlation between the ferrocene head coverage on the electrodes, determined by $\mathrm{CV}$, and the intensity of the corresponding SWV signals. Estimation of the concentration of ferrocene heads "seen" by the enzyme. Production of holo-GDH. Preparation and characterization of the GDH-IgG conjugate. This information is available free of charge via the Internet at http: //pubs.acs.org.

\section{Acknowledgments.}

Dr. Nicolas Mano is warmly thanked for providing the pgp492 plasmid used to produce PQQ-GDH. We thank Drs. Benoit Limoges, François Mavré and Mathieu Branca for the generous gift of a PQQ sample. Vincent Guérineau, www.imagif.cnrs.fr, is thanked for Maldi-Tof mass spectrometry analysis. This work has received financial support from the French "Agence Nationale de la Recherche" (ANR) through “eVIRZYM” (DS0401 - ANR 2014-CE09-0009). 


\section{References}

(1) Bollella, P.; Gorton, L. Enzyme Based Amperometric Biosensors. Curr. Opin. Electrochem. 2018, $10,157-173$.

(2) Meredith, M. T.; Minteer, S. D. Biofuel Cells: Enhanced Enzymatic Bioelectrocatalysis. Annu. Rev. Anal. Chem. 2012, 5, 157-179.

(3) Holzinger, M.; Le Goff, A.; Cosnier, S. Nanomaterials for Biosensing Applications: A Review. Front. Chem. 2014, 2, 63.

(4) Zhu, C.; Yang, G.; Li, H.; Du, D.; Lin, Y. Electrochemical Sensors and Biosensors Based on Nanomaterials and Nanostructures. Anal. Chem. 2015, 87, 230-249.

(5) Zhao, C.; Gai, P.; Song, R.; Chen, Y.; Zhang, J.; Zhu, J.-J. Nanostructured Material-Based Biofuel Cells: Recent Advances and Future Prospects. Chem. Soc. Rev. 2017, 46, 1545-1564.

(6) De Poulpiquet, A.; Ciaccafava, A.; Lojou, E. New Trends in Enzyme Immobilization at Nanostructured Interfaces for Efficient Electrocatalysis in Biofuel Cells. Electrochim. Acta 2014, $126,104-114$.

(7) Milton, R. D.; Wang, T.; Knoche, K. L.; Minteer, S. D. Tailoring Biointerfaces for Electrocatalysis. Langmuir 2016, 32, 2291-2301.

(8) Heller, A. Electrical Wiring of Redox Enzymes. Acc. Chem. Res. 1990, 23, 128-134.

(9) Gao, F.; Viry, L.; Maugey, M.; Poulin, P.; Mano, N. Engineering Hybrid Nanotube Wires for HighPower Biofuel Cells. Nat. Commun. 2010, 1, 2.

(10) Cortez, M. L.; Marmisollé, W.; Pallarola, D.; Pietrasanta, L. I.; Murgida, D. H.; Ceolín, M.; Azzaroni, O.; Battaglini, F. Effect of Gold Nanoparticles on the Structure and Electron-Transfer Characteristics of Glucose Oxidase Redox Polyelectrolyte-Surfactant Complexes. Chem. - A Eur. 
J. 20, 13366-13374.

(11) Aquino Neto, S.; Milton, R. D.; Crepaldi, L. B.; Hickey, D. P.; De Andrade, A. R.; Minteer, S. D. Co-Immobilization of Gold Nanoparticles with Glucose Oxidase to Improve Bioelectrocatalytic Glucose Oxidation. J. Power Sources 2015, 285, 493-498.

(12) Callegari, A.; Cosnier, S.; Marcaccio, M.; Paolucci, D.; Paolucci, F.; Georgakilas, V.; Tagmatarchis, N.; Vázquez, E.; Prato, M. Functionalised Single Wall Carbon Nanotubes/Polypyrrole Composites for the Preparation of Amperometric Glucose Biosensors. $J$. Mater. Chem. 2004, 14, 807-810.

(13) Nazaruk, E.; Sadowska, K.; Biernat, J. F.; Rogalski, J.; Ginalska, G.; Bilewicz, R. Enzymatic Electrodes Nanostructured with Functionalized Carbon Nanotubes for Biofuel Cell Applications. Anal. Bioanal. Chem. 2010, 398, 1651-1660.

(14) Deng, L.; Liu, Y.; Yang, G.; Shang, L.; Wen, D.; Wang, F.; Xu, Z.; Dong, S. Molecular “Wiring” Glucose Oxidase in Supramolecular Architecture. Biomacromolecules 2007, 8, 2063-2071.

(15) Haddad, R.; Mattei, J. G.; Thery, J.; Auger, A. Novel Ferrocene-Anchored ZnO Nanoparticle/Carbon Nanotube Assembly for Glucose Oxidase Wiring: Application to a Glucose/Air Fuel Cell. Nanoscale 2015, 7, 10641-10647.

(16) Trifonov, A.; Herkendell, K.; Tel-Vered, R.; Yehezkeli, O.; Woerner, M.; Willner, I. EnzymeCapped Relay-Functionalized Mesoporous Carbon Nanoparticles: Effective Bioelectrocatalytic Matrices for Sensing and Biofuel Cell Applications. ACS Nano 2013, 7, 11358-11368.

(17) Riedel, M.; Sabir, N.; Scheller, F. W.; Parak, W. J.; Lisdat, F. Connecting Quantum Dots with Enzymes: Mediator-Based Approaches for the Light-Directed Read-out of Glucose and Fructose Oxidation. Nanoscale 2017, 9, 2814-2823.

(18) Nguyen, K. Van; Holade, Y.; Minteer, S. D. DNA Redox Hydrogels: Improving Mediated 
Enzymatic Bioelectrocatalysis. ACS Catal. 2016, 6, 2603-2607.

(19) Piperberg, G.; Wilner, O. I.; Yehezkeli, O.; Tel-Vered, R.; Willner, I. Control of Bioelectrocatalytic Transformations on DNA Scaffolds. J. Am. Chem. Soc. 2009, 131, 8724-8725.

(20) Van Nguyen, K.; Giroud, F.; Minteer, S. D. Improved Bioelectrocatalytic Oxidation of Sucrose in a Biofuel Cell with an Enzyme Cascade Assembled on a DNA Scaffold. J. Electrochem. Soc. 2014, 161, H930-H933.

(21) Carette, N.; Engelkamp, H.; Akpa, E.; Pierre, S. J.; Cameron, N. R.; Christianen, P. C. M.; Maan, J. C.; Thies, J. C.; Weberskirch, R.; Rowan, A. E.; Nolte, R. J. M.; Michon, T.; Van Hest, J. C. M. A Virus-Based Biocatalyst. Nat. Nanotechnol. 2007, 2, 226-229.

(22) Cardinale, D.; Carette, N.; Michon, T. Virus Scaffolds as Enzyme Nano-Carriers. Trends Biotechnol. 2012, 30, 369-376.

(23) Minten, I. J.; Claessen, V. I.; Blank, K.; Rowan, A. E.; Nolte, R. J. M.; Cornelissen, J. J. L. M. Catalytic Capsids: The Art of Confinement. Chem. Sci. 2011, 2, 358-362.

(24) Aljabali, A. A. A.; Barclay, J. E.; Steinmetz, N. F.; Lomonossoff, G. P.; Evans, D. J. Controlled Immobilisation of Active Enzymes on the Cowpea Mosaic Virus Capsid. Nanoscale 2012, 4, $5640-5645$.

(25) Patterson, D. P.; Schwarz, B.; El-Boubbou, K.; Van Der Oost, J.; Prevelige, P. E.; Douglas, T. Virus-like Particle Nanoreactors: Programmed Encapsulation of the Thermostable CelB Glycosidase inside the P22 Capsid. Soft Matter 2012, 8, 10158-10166.

(26) Pille, J.; Cardinale, D.; Carette, N.; Di Primo, C.; Besong-Ndika, J.; Walter, J.; Lecoq, H.; Van Eldijk, M. B.; Smits, F. C. M.; Schoffelen, S.; Van Hest, J. C. M.; Mäkinen, K.; Michon, T. General Strategy for Ordered Noncovalent Protein Assembly on Well-Defined Nanoscaffolds. Biomacromolecules 2013, 14, 4351-4359. 
(27) Rurup, W. F.; Koay, M. S. T.; Cornelissen, J. J. L. M. Viruses as Model Nanoreactors to Study Enzyme Kinetics. In Enzyme Nanocarriers; Cardinale, D., Michon, T., Eds.; Taylor \& Francis Group: New York, NY, 2015; pp 105-122.

(28) Cuenca, S.; Mansilla, C.; Aguado, M.; Yuste-Calvo, C.; Sánchez, F.; Sánchez-Montero, J. M.; Ponz, F. Nanonets Derived from Turnip Mosaic Virus as Scaffolds for Increased Enzymatic Activity of Immobilized Candida Antarctica Lipase B. Front. Plant Sci. 2016, 7, 464.

(29) Timmermans, S. B. P. E.; Van Hest, J. C. M. Self-Assembled Nanoreactors Based on Peptides and Proteins. Curr. Opin. Colloid Interface Sci. 2018, 35, 26-35.

(30) Koch, C.; Wabbel, K.; Eber, F. J.; Krolla-Sidenstein, P.; Azucena, C.; Gliemann, H.; Eiben, S.; Geiger, F.; Wege, C. Modified TMV Particles as Beneficial Scaffolds to Present Sensor Enzymes. Front. Plant Sci. 2015, 6, 1137.

(31) Bäcker, M.; Koch, C.; Eiben, S.; Geiger, F.; Eber, F.; Gliemann, H.; Poghossian, A.; Wege, C.; Schöning, M. J. Tobacco Mosaic Virus as Enzyme Nanocarrier for Electrochemical Biosensors. Sensors Actuators, B Chem. 2017, 238, 716-722.

(32) Koch, C.; Poghossian, A.; Schöning, M. J.; Wege, C. Penicillin Detection by Tobacco Mosaic Virus -Assisted Colorimetric Biosensors . Nanotheranostics 2018, 2, 184-196.

(33) Blaik, R. A.; Lan, E.; Huang, Y.; Dunn, B. Gold-Coated M13 Bacteriophage as a Template for Glucose Oxidase Biofuel Cells with Direct Electron Transfer. ACS Nano 2016, 10, 324-332.

(34) Patel, A. N.; Anne, A.; Chovin, A.; Demaille, C.; Grelet, E.; Michon, T.; Taofifenua, C. Scaffolding of Enzymes on Virus Nanoarrays: Effects of Confinement and Virus Organization on Biocatalysis. Small 2017, 13, 1603163.

(35) Patterson, D. P.; Schwarz, B.; Waters, R. S.; Gedeon, T.; Douglas, T. Encapsulation of an Enzyme Cascade within the Bacteriophage P22 Virus-like Particle. ACS Chem. Biol. 2014, 9, 359-365. 
(36) Besong-Ndika, J.; Wahlsten, M.; Cardinale, D.; Pille, J.; Walter, J.; Michon, T.; Mäkinen, K. Towards the Reconstitution of a Two-Enzyme Cascade for Resveratrol Synthesis on Potyvirus Particles. Front. Plant Sci. 2016, 7, 89.

(37) Brasch, M.; Putri, R. M.; De Ruiter, M. V.; Luque, D.; Koay, M. S. T.; Caston, J. R.; Cornelissen, J. J. L. M. Assembling Enzymatic Cascade Pathways inside Virus-Based Nanocages Using DualTasking Nucleic Acid Tags. J. Am. Chem. Soc. 2017, 139, 1512-1519.

(38) Steinmetz, N. F.; Lomonossoff, G. P.; Evans, D. J. Decoration of Cowpea Mosaic Virus with Multiple, Redox-Active, Organometallic Complexes. Small 2006, 2, 530-533.

(39) Nault, L.; Taofifenua, C.; Anne, A.; Chovin, A.; Demaille, C.; Besong-Ndika, J.; Cardinale, D.; Carette, N.; Michon, T.; Walter, J. Electrochemical Atomic Force Microscopy Imaging of RedoxImmunomarked Proteins on Native Potyviruses: From Subparticle to Single-Protein Resolution. ACS Nano 2015, 9, 4911-4924.

(40) Aljabali, A. A. A.; Barclay, J. E.; Butt, J. N.; Lomonossoff, G. P.; Evans, D. J. Redox-Active Ferrocene-Modified Cowpea Mosaic Virus Nanoparticles. Dalt. Trans. 2010, 39, 7569-7574.

(41) Mao, C.; Liu, A.; Cao, B. Virus-Based Chemical and Biological Sensing. Angew. Chemie - Int. Ed. 2009, 48, 6790-6810.

(42) Peltomaa, R.; López-Perolio, I.; Benito-Peña, E.; Barderas, R.; Moreno-Bondi, M. C. Application of Bacteriophages in Sensor Development. Anal. Bioanal. Chem. 2016, 408, 1805-1828.

(43) Bhasin, A.; Ogata, A. F.; Briggs, J. S.; Tam, P. Y.; Tan, M. X.; Weiss, G. A.; Penner, R. M. The Virus Bioresistor: Wiring Virus Particles for the Direct, Label-Free Detection of Target Proteins. Nano Lett. 2018, 18, 3623-3629.

(44) Anne, A.; Demaille, C.; Moiroux, J. Elastic Bounded Diffusion. Dynamics of Ferrocene-Labeled Poly(Ethylene Glycol) Chains Terminally Attached to the Outermost Monolayer of Successively 
Self-Assembled Monolayers of Immunoglobulins. J. Am. Chem. Soc. 1999, 121, 10379-10388.

(45) Bourdillon, C.; Demaille, C.; Moiroux, J.; Savéant, J.-M. Step-by-Step Immunological Construction of a Fully Active Multilayer Enzyme Electrode. J. Am. Chem. Soc. 1994, 116, 1032810329.

(46) Pease, L. F.; Elliott, J. T.; Tsai, D.-H.; Zachariah, M. R.; Tarlov, M. J. Determination of Protein Aggregation with Differential Mobility Analysis: Application to IgG Antibody. Biotechnol. Bioeng. 2008, 101, 1214-1222.

(47) Oubrie, A.; Rozeboom, H. J.; Kalk, K. H.; Duine, J. A.; Dijkstra, B. W. The 1.7 Å Crystal Structure of the Apo Form of the Soluble Quinoprotein Glucose Dehydrogenase from Acinetobacter Calcoaceticus Reveals a Novel Internal Conserved Sequence Repeat. J. Mol. Biol. 1999, 289, 319333.

(48) Kuznetsov, Y. G.; McPherson, A. Atomic Force Microscopy in Imaging of Viruses and VirusInfected Cells. Microbiol. Mol. Biol. Rev. 2011, 75, 268-295.

(49) Anne, A.; Chovin, A.; Demaille, C.; Lafouresse, M. High-Resolution Mapping of RedoxImmunomarked Proteins Using Electrochemical-Atomic Force Microscopy in Molecule Touching Mode. Anal. Chem. 2011, 83, 7924-7932.

(50) Anne, A.; Demaille, C.; Moiroux, J. Elastic Bounded Diffusion and Electron Propagation: Dynamics of the Wiring of a Self-Assembly of Immunoglobulins Bearing Terminally Attached Ferrocene Poly(Ethylene Glycol) Chains According to a Spatially Controlled Organization. J. Am. Chem. Soc. 2001, 123, 4817-4825.

(51) Laviron, E. General Expression of the Linear Potential Sweep Voltammogram in the Case of Diffusionless Electrochemical Systems. J. Electroanal. Chem. 1979, 101, 19-28.

(52) Anicet, N.; Anne, A.; Bourdillon, C.; Demaille, C.; Moiroux, J.; Savéant, J. M. Electrochemical 
Approach to the Dynamics of Molecular Recognition of Redox Enzyme Sites by Artificial Cosubstrates in Solution and in Integrated Systems. Faraday Discuss. 2000, 116, 269-279.

(53) Witarto, A. B.; Ohtera, T.; Sode, K. Site-Directed Mutagenesis Study on the Thermal Stability of a Chimeric PQQ Glucose Dehydrogenase and Its Structural Interpretation. Appl. Biochem. Biotechnol. - Part A Enzym. Eng. Biotechnol. 1999, 77, 159-168.

(54) Shen, D.; Meyerhoff, M. E. Pyrroloquinoline Quinone-Doped Polymeric Nanospheres as Sensitive Tracer for Binding Assays. Anal. Chem. 2009, 81, 1564-1569.

(55) Zimmerman, L. B.; Lee, K. D.; Meyerhoff, M. E. Visual Detection of Single-Stranded Target DNA Using Pyrroloquinoline-Quinone-Loaded Liposomes as a Tracer. Anal. Biochem. 2010, 401, 182187.

(56) Zimmermann, K.; Hagedorn, H.; Heuck, C. C.; Hinrichsen, M.; Ludwig, H. The Ionic Properties of the Filamentous Bacteriophages Pf1 and Fd. J. Biol. Chem. 1986, 261, 1653-1655.

(57) Grelet, E.; Rana, R. From Soft to Hard Rod Behavior in Liquid Crystalline Suspensions of Sterically Stabilized Colloidal Filamentous Particles. Soft Matter 2016, 12, 4621-4627.

(58) Flexer, V.; Mano, N. Wired Pyrroloquinoline Quinone Soluble Glucose Dehydrogenase Enzyme Electrodes Operating at Unprecedented Low Redox Potential. Anal. Chem. 2014, 86, 2465-2473.

(59) Mazurenko, I.; Monsalve, K.; Infossi, P.; Giudici-Orticoni, M. T.; Topin, F.; Mano, N.; Lojou, E. Impact of Substrate Diffusion and Enzyme Distribution in 3D-Porous Electrodes: A Combined Electrochemical and Modelling Study of a Thermostable H2/O2 Enzymatic Fuel Cell. Energy Environ. Sci. 2017, 10, 1966-1982.

(60) Costentin, C.; Savéant, J.-M. Towards an Intelligent Design of Molecular Electrocatalysts. Nat. Rev. Chem. 2017, 1, 87. 
(61) Voiry, D.; Chhowalla, M.; Gogotsi, Y.; Kotov, N. A.; Li, Y.; Penner, R. M.; Schaak, R. E.; Weiss, P. S. Best Practices for Reporting Electrocatalytic Performance of Nanomaterials. ACS Nano 2018, $12,9635-9638$.

(62) Bourdillon, C.; Demaille, C.; Gueris, J.; Moiroux, J.; Savéant, J.-M. A Fully Active Monolayer Enzyme Electrode Derivatized by Antigen-Antibody Attachment. J. Am. Chem. Soc. 1993, 115, $12264-12269$.

(63) Olsthoorn, A. J. J.; Otsuki, T.; Duine, J. A. Negative Cooperativity in the Steady-State Kinetics of Sugar Oxidation by Soluble Quinoprotein Glucose Dehydrogenase from Acinetobacter Calcoaceticus. Eur. J. Biochem. 1998, 255, 255-261.

(64) Durand, F.; Limoges, B.; Mano, N.; Mavré, F.; Miranda-Castro, R.; Savéant, J. M. Effect of Substrate Inhibition and Cooperativity on the Electrochemical Responses of Glucose Dehydrogenase. Kinetic Characterization of Wild and Mutant Types. J. Am. Chem. Soc. 2011, 133, $12801-12809$.

(65) Zhang, L.; Miranda-Castro, R.; Stines-Chaumeil, C.; Mano, N.; Xu, G.; Mavré, F.; Limoges, B. Heterogeneous Reconstitution of the PQQ-Dependent Glucose Dehydrogenase Immobilized on an Electrode: A Sensitive Strategy for PQQ Detection down to Picomolar Levels. Anal. Chem. 2014, $86,2257-2267$.

(66) Yoo, P. J.; Nam, K. T.; Belcher, A. M.; Hammond, P. T. Solvent-Assisted Patterning of Polyelectrolyte Multilayers and Selective Deposition of Virus Assemblies. Nano Lett. 2008, 8, $1081-1089$.

(67) Sambrook, J.; Fritsch, E. F.; Maniatis, T. Molecular Cloning: A Laboratory Manual.; New-York, 1989.

(68) Huang, K.; Anne, A.; Bahri, M. A.; Demaille, C. Probing Individual Redox PEGylated Gold 
Nanoparticles by Electrochemical-Atomic Force Microscopy. ACS Nano 2013, 7, 4151-4163.

(69) Abbou, J.; Demaille, C.; Druet, M.; Moiroux, J. Fabrication of Submicrometer-Sized Gold Electrodes of Controlled Geometry for Scanning Electrochemical-Atomic Force Microscopy. Anal. Chem. 2002, 74, 6355-6363. 


\section{Graphical Table of Contents}

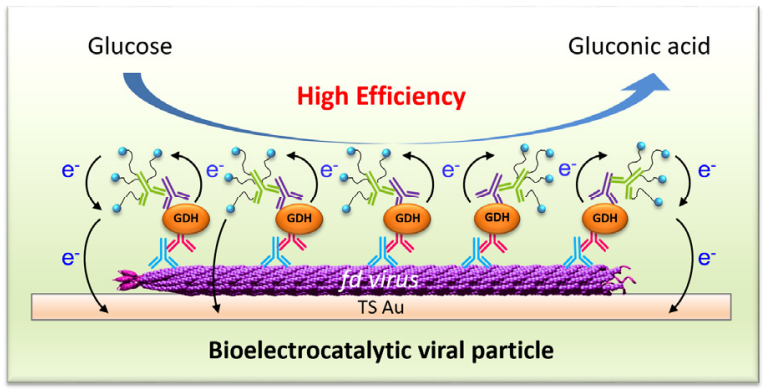

